\title{
Modelling and Predictive Study of Hydrothermal Liquefaction: Application to Food Processing Residues
}

\author{
Maxime Déniel $^{1,2}$ - Geert Haarlemmer ${ }^{1}$ - Anne Roubaud ${ }^{1} \cdot$ Elsa Weiss-Hortala $^{2}$. \\ Jacques Fages ${ }^{2}$
}

\begin{abstract}
Thermochemical processes are promising ways for energy valorization of biomass and waste, but suffer from a lack of predictability. In this work, we focus on using model molecules to model the behavior of wet organic residues during hydrothermal liquefaction (HTL), a process used to produce bio based liquid fuels from wet biomass. Monomeric and polymeric model molecules were used as modelling tools to study HTL of real resources. Experiments with model mixtures and four food processing residues (blackcurrant pomace, raspberry achenes, brewer's spent grains, grape marc) were conducted at $300{ }^{\circ} \mathrm{C}, 60 \mathrm{~min}$ holding time and a dry matter concentration of $15 \mathrm{wt} \%$. To elaborate model mixtures, four model monomers (glucose, guaiacol, glutamic acid, linoleic acid) and two model polymers (microcrystalline cellulose, alkali lignin) were selected from characterization of blackcurrant pomace. HTL of model mixtures reproduced HTL of blackcurrant pomace with acceptable representative ness, but results showed that model mixtures should include polymers to represent the fiber content of the resource. Results of HTL of model compounds were used to elaborate poly nomial correlations able to predict experimental yields as a function of the initial biomass composition. Calculations were within -8.0 to $+4.8 \mathrm{wt} \%$ of experimental yields obtained by HTL of real food processing residues, showing a good
\end{abstract}

Electronic supplementary material The online version of this article (doi:10.1007/s12649 0169726 7) contains supplementary material, which is available to authorized users.

$\triangle$ Geert Haarlemmer geert.haarlemmer@cea.fr

1 Laboratoire de Thermo Conversion des Bioressources, CEA LITEN, 17 rue des Martyrs, 38054 Grenoble, France

2 CNRS Centre RAPSODEE, Ecole des Mines d'Albi, Université de Toulouse, 81013 Albi, France accuracy of the correlations. These expressions also showed good agreement with HTL results reported in the literature for other resources, and could be useful to assess the potential of various kinds of bioresources for HTL.

Keywords Hydrothermal liquefaction · Model compounds · Food processing residues · Bio oil · Polynomial regression - Mixture designs
Abbreviations
ADF Acid detergent fibers
ADL Acid detergent lignin
BSG Brewer's spent grains
daf Dry ash free
DOE Design of experiments
HHV Higher heating value ( $\mathrm{MJ} \mathrm{kg}^{-1}$ )
HTL Hydrothermal liquefaction
NDF Neutral detergent fibres
Variables
$\mathrm{b}_{\mathrm{i}}$
$b_{i j}$
Linear contribution coefficient of model compound $i$
Binary interaction coefficient between model compound $i$ and model compound $j$
F Value of the $F$ test
$\mathrm{m}_{\mathrm{BO}}, \mathrm{m}_{\mathrm{C}}, \mathrm{m}_{\mathrm{G}}, \mathrm{m}_{\mathrm{In}} \quad$ Mass of bio oil, char, gas, initial dry and $\mathrm{m}_{\mathrm{R}}$ ash free matter and raw organic residue $(\mathrm{g})$, respectively
$\mathrm{M}_{\mathrm{j}}$ Molar mass of gaseous species $j\left(\mathrm{~g} \mathrm{~mol}^{-1}\right)$
$\mathrm{n}$ Total number of experiments
$\mathrm{p}$ ( $p=4$ for the linear model, $p=10$ for the quadratic model) 


\begin{tabular}{|c|c|}
\hline $\mathrm{P}_{\mathrm{i}}, \mathrm{P}_{\mathrm{f}}$ & $\begin{array}{l}\text { Initial and final pressures in the } \\
\text { reactor }(\mathrm{Pa}) \text {, respectively }\end{array}$ \\
\hline q & $\begin{array}{l}\text { Number of model compounds in the } \\
\text { DOE }\end{array}$ \\
\hline $\mathrm{R}$ & $\begin{array}{l}\text { Ideal gas constant } \\
\left(8.314 \mathrm{~J} \mathrm{~K}^{-1} \mathrm{~mol}^{-1}\right)\end{array}$ \\
\hline $\mathrm{SD}_{\mathrm{bi}(\text { or bij) }}$ & $\begin{array}{l}\text { Standard deviation on the } \\
\text { contribution coefficient } b_{i}\left(\text { or } b_{i j}\right)\end{array}$ \\
\hline SSO & $\begin{array}{l}\text { Proportion of solvent soluble } \\
\text { organics in the raw organic residue } \\
(\mathrm{wt} \%)\end{array}$ \\
\hline $\mathrm{t}$ & Value of the student test \\
\hline $\mathrm{T}_{\mathrm{i}}, \mathrm{T}_{\mathrm{f}}$ & $\begin{array}{l}\text { Initial and final temperatures in the } \\
\text { reactor }(\mathrm{K})\end{array}$ \\
\hline $\mathrm{V}_{\mathrm{G}}$ & $\begin{array}{l}\text { Volume of gaseous phase in the } \\
\text { reactor }\left(\mathrm{m}^{3}\right)\end{array}$ \\
\hline $\mathrm{W}_{\mathrm{R}}$ & $\begin{array}{l}\text { Water content of the raw organic } \\
\text { residue (wt } \% \text { ) }\end{array}$ \\
\hline$x_{i}, x_{j}$ & $\begin{array}{l}\text { Mass fraction of model compound } \\
i \text { or } j \text { in the mixture or in the } \\
\text { biomass, respectively }\end{array}$ \\
\hline$\overline{\mathrm{y}}$ & $\begin{array}{l}\text { Mean value of the experimental } \\
\text { responses }\end{array}$ \\
\hline $\mathrm{Y}$ & $\begin{array}{l}\text { Experimental response (e.g. mass } \\
\text { yield of bio oil) }\end{array}$ \\
\hline $\mathrm{Y}_{\mathrm{i}}$ & $\begin{array}{l}\text { Experimental response of a single } \\
\text { model compound }\end{array}$ \\
\hline $\mathrm{y}_{\mathrm{j}}$ & Molar fraction of gaseous species $j$ \\
\hline $\mathrm{y}_{\mathrm{k}}$ & $\begin{array}{l}\text { Measured experimental response for } \\
\text { experiment } \mathrm{k}\end{array}$ \\
\hline$\hat{y}_{k}$ & $\begin{array}{l}\text { Calculated experimental response } \\
\text { for experiment } k\end{array}$ \\
\hline $\begin{array}{l}\mathrm{Y}_{\mathrm{A}}, \mathrm{Y}_{\mathrm{BO}}, \mathrm{Y}_{\mathrm{C}} \text { and } \\
\mathrm{Y}_{\mathrm{G}}\end{array}$ & $\begin{array}{l}\text { Yield of organic matter in aqueous } \\
\text { phase, yields of bio oil, char and gas } \\
\text { (wt } \% \text { of initial dry ash free matter), } \\
\text { respectively }\end{array}$ \\
\hline
\end{tabular}

\section{Introduction}

Rising concerns about climate change, associated with increasing energy demand worldwide, has put the search for substitution of fossil fuels by renewable fuels on the front scene in recent years. Many biochemical and ther mochemical technologies are currently under development to produce renewable fuels from biomass and organic residues [1]. The development of these technologies faces several challenges, among which is the lack of ability to predict the products of the process (e.g. bio oil, char, gas) based on the nature and characterization of the starting biomass. In this context, efforts should be made to provide predictive tools.

This work focuses on the conversion of food processing residues into bio oils through hydrothermal liquefaction, in order to study one predictive methodology. Food processing residues contain valuable organics that could be recovered either as high value compounds or bio based fuels. They currently represent more than $20 \%$ of the total agricultural production worldwide, generated at every stage of the food supply chain, from harvesting to final consumption. Effi cient management and valorization of these waste streams are necessary to avoid environmental and sanitary conse quences of their disposal [2]. To convert these resources into bio oils, the hydrothermal liquefaction (HTL) process has been selected, as it is currently receiving significant and increasing attention regarding energy valorization of wet biomass and organic residues. Hydrothermal liquefaction is a thermal process used to convert wet biomass. Under sub critical water conditions of temperature $\left(250400{ }^{\circ} \mathrm{C}\right)$ and pressure (10 $30 \mathrm{MPa}$ ), biomass is depolymerized giving among several several products , a bio oil with high energy content. This process takes advantage of the specific prop erties of water properties in the subcritical region to degrade wet biomass through many reactions [3 5], converting it into renewable liquid fuels [6,7]. Through this process, biomass is converted into four streams: a biocrude or bio oil with higher heating values up to $3540 \mathrm{MJ} \mathrm{kg}^{-1}$, an aque ous phase containing platform chemicals, a solid residue referred to as char and a $\mathrm{CO}_{2}$ rich gaseous phase. Hydrothermal liquefaction has been applied to a wide range of resources from wood [8] to algae [9] and food processing residues [10] both at the laboratory and at the pilot scale.

Despite a large number of studies on various types of biomass, the HTL process lacks of predictability regarding the products distribution, which highly depends on the nature of the starting material [11]. Reaction mechanisms behind HTL are still badly understood, both because of the numerous reaction pathways and the complex composition of starting materials. One way to get insights of the fun damental mechanisms behind HTL is to simplify reaction systems by using model molecules. Reaction schemes and kinetics of single model monomers have been extensively studied, but significantly less information is reported in the literature regarding the behavior of complex model mix tures [10]. While detailed kinetic approaches are interest ing to get an exhaustive understanding of the chemistry behind HTL, they do not often link the initial biomass composition (fibers, proteins, lipids...) with the mass yields of the products. This approach might be of interest in the development of HTL technologies applied to a broad range of different substrates.

To date, only few published studies have focused on linking the products distribution of HTL with the initial composition of the substrate, focusing on algal biomass. Biller and Ross [12] studied HTL of several model compounds as surrogates for algal biomass, at $350{ }^{\circ} \mathrm{C}$ and $200 \mathrm{bar}$ for $60 \mathrm{~min}$. Model compounds were two model proteins (albumin, soya protein) and two model 
amino acids (asparagine, glutamine), one model polysaccharide (starch) and one model monosaccharide (glucose), as well as one model lipid (sunflower oil). They found that the contributions of individual species to the bio oil formation was in the order lipids $>$ pro teins $>$ carbohydrates, and used an additive rule to model the bio oil yield as a function of the initial algae composition. This correlation showed a good agreement with experimental results from a model mixture, as well as two algae strains, but did not fit for three other strains, suggesting a more complex behavior (including interaction reactions). Valdez et al. [13] developed a kinetic model based on a reaction network using the biochemical composition of microalgae (lipid, protein and carbohydrate). They calculated the evolution of the product distribution with temperature $\left(250400{ }^{\circ} \mathrm{C}\right)$ and time (0 $60 \mathrm{~min}$ ) and obtained a good agreement with experimental values for the three tested algae strains (Nannochloropsis sp., C. protothecoides and Scene desmus sp.). Their results confirmed those of Biller and Ross [12], suggesting higher contributions of lipids and proteins to bio oil formation. Teri et al. [14] used six model compounds (cornstarch, cellulose, soya protein, albumin, sunflower oil and castor oil) to investigate HTL of algal biomass at 300 and $350{ }^{\circ} \mathrm{C}$. In this work, they used a mass averaged model and a quadratic model taking into account binary interactions and obtained a good predictability towards HTL of ternary model mix tures with both models. Yet, the authors did not test the correlations against experimental results from HTL of actual algae strains. Yang et al. [15] used pure and binary mixtures of crude extractives (polysaccharides and proteins) from algae, to investigate HTL of low lipid algae. They used a mass averaged model to correlate the mass yields to the composition of the biomass. Their results showed that polysaccharides had a small contri bution to the bio oil formation compared to proteins. Results obtained with polysaccharide protein mixtures led them to conclude that the bio oil yield did not vary linearly, and that interactions between polysaccharides and proteins had a significant effect on the bio oil recovery. Finally, Leow et al. [16] developed an addi tivity model to predict the bio oil yield, based on HTL experiments using Nannochloropsis oculata with differ ent biochemical compositions. The additivity model was more accurate than others based on model compounds. The authors also proposed an alternative model based on the contribution of the lipid content (amount and nature of fatty acids) and the non lipid contribution, allowing to predict with good accuracy the bio oil and aqueous phase yields, as well as several other properties of the bio oil (nitrogen content, elemental composition...) This approach is however more complex than a simpler proximate analysis, as it requires full characterization of the lipids in the biomass and HTL runs with a defatted resource. Previous works have only been focused on algal biomass, and do not consider the case of organic waste which may contain lignocellulosic biomass. In addition, previous studies have mainly been focused on the bio oil phase rather than on the global products distribution. Finally, while mathematical models are confronted to model mixtures, calculated yields are rarely compared with experimental results obtained from actual resources.

The objective of the present paper is to show how the use of model compounds provides insights on the conver sion of real biomass. To that end, we have studied hydrothermal conversion of model compounds alone, as well as in mixtures of two to four compounds. Represen tative model molecules were chosen from the molecular characterization of a reference biomass (blackcurrant pomace). Results of HTL experiments on model com pounds were used to elaborate predictive correlations for mass yields, which were then tested against results of hydrothermal liquefaction of other food processing resi dues; namely blackcurrant pomace, raspberry achenes, brewer's spent grains (BSG) and grape marc; before being tested against literature results for a larger scope of resources.

\section{Materials and Methods}

In this section, we first present the general approach fol lowed in this work. Characterization of the several resources tested is then reported, as well as other materials used to perform the experiments. Design of experiments and mathematical models are also explained. Finally, we give details on the experimental procedure for HTL experiments and recovery of products.

\section{General Methodology}

The aim of the work is to compare hydrothermal lique faction of model mixtures with hydrothermal liquefaction of actual food processing residues. To that end, black currant pomace was chosen as a reference biomass. The molecular characterization of this resource was used to select representative model compounds, which were hydrothermally converted alone and in mixtures. Results of the experiments on model compounds were used to elaborate predictive correlations for mass yields, which were then tested against results of hydrothermal lique faction of other food processing residues, namely rasp berry achenes, brewer's spent grains (BSG) and grape marc. 


\section{Materials}

Characterization of Food Processing Residues for the Selection of Model Molecules

Table 1 reports the results of the analysis of the four food processing residues used in this study. They were all sup plied by local producers operating in the south east of France.

The resources are highly fibrous, even though the nature of the fibers differs. In fact, BSG are rich in cellulosic fibers (high $N D F$ content, low $A D L$ content) while the other three are more lignin rich. In terms of protein content, blackcurrant pomace and BSG are richer than raspberry achenes and grape marc. Lipid contents are relatively low for all resources, varying from 5.2 to $14.8 \mathrm{wt} \%$.

As explained in "General Methodology" section, the choice of model molecules was based on the characteri zation of blackcurrant pomace. This residue is the press cake recovered after berry pressing of two mixed cultivars (Noir de Bourgogne and Andega). It is mainly constituted by seeds, peels and pulp. As can be seen from Table 1, blackcurrant pomace is a wet and fibrous resource. Espe cially, the $A D F$ and $A D L$ contents are high, meaning that the biomass is both rich in cellulose and lignin. The first focus of the work was to study hydrothermal conversion of model monomers: glucose was therefore chosen to repre sent the cellulosic content in blackcurrant pomace (cellu lose, xyloglucan hemicelluloses and free sugars), while guaiacol was chosen as a representative monomer for lig nin. In addition to monomers, microcrystalline cellulose and lignin (alkali) were used as model compounds to rep resent the fibers contained in blackcurrant pomace.

From Table 1, we also see that blackcurrant pomace contains a non negligible amount of proteins and lipids.
From the amino acid and fatty acid profiles reported in Fig. 1, glutamic acid and linoleic acid were chosen to represent proteins and lipids, respectively. Model polymers were not considered in the case of proteins and lipids, for two different reasons. Firstly, amino acids and proteins have a very similar reactivity during HTL, as observed in previous studies [12, 20, 21]. Secondly, lipids are mainly present in the form of triglycerides in biomass: fatty acids account for up to $98 \mathrm{wt} \%$ in these particular structures, glycerol is therefore considered as negligible in this study.

\section{Chemicals}

Microcrystalline cellulose, lignin (alkali, low sulfonate content), glutamic acid and linoleic acid were purchased from Sigma Aldrich and used as received. HTL experi ments were performed using distilled water as the reaction solvent. Ethyl acetate used for bio oil recovery was pur chased from Sigma Aldrich and used as received.

\section{Design of Experiments}

\section{Experimental Points}

Design of experiments (DOE) for hydrothermal lique faction of model compounds was based on specific designs called mixture designs, in which the variables are the composition of each compound in the mixture. In a mixture DOE, variables depend on each other, as the sum of compositions must equal $100 \%$. In this work, two types of designs were used: Scheffe designs $(4,2)$, also known as simplex lattice designs, and axial mixture designs. While the former only includes pure composi tions and binary mixtures in equal proportions, the latter also include ternary and quaternary mixtures. The

Table 1 Characterization of blackcurrant pomace, raspberry achenes, brewer's spent grains (BSG) and grape marc used in this work

\begin{tabular}{|c|c|c|c|c|c|}
\hline & $\begin{array}{l}\text { Blackcurrant } \\
\text { pomace }\end{array}$ & $\begin{array}{l}\text { Raspberry } \\
\text { achenes }\end{array}$ & $\begin{array}{l}\text { Brewer's spent } \\
\text { grains (BSG) }\end{array}$ & $\begin{array}{l}\text { Grape marc } \\
\text { (dried, ground) }\end{array}$ & Standard \\
\hline Moisture content (wt\%) & 59.6 & 44.4 & 70.1 & 7.4 & EN 147741 [17] \\
\hline Fiber content (wt $\%$ of dry matter) & & & & & NF V18 122 [18] \\
\hline NDF (neutral detergent fibers) & 61.7 & 83.3 & 35.5 & 69.9 & \\
\hline ADF (acid detergent fibers) & 52.8 & 74.3 & 11.4 & 63.4 & \\
\hline ADL (acid detergent lignin) & 34.6 & 47.2 & 5.9 & 48.6 & \\
\hline Cellulose $(A D F A D L)$ & 18.2 & 27.1 & 5.5 & 14.8 & \\
\hline Hemicelluloses (NDF ADF) & 8.8 & 9.0 & 24.1 & 6.5 & \\
\hline Lignin $(A D L)$ & 34.6 & 47.2 & 5.9 & 48.6 & \\
\hline Proteins (wt $\%$ of dry matter) & $16.9( \pm 0.8)$ & $8.1( \pm 0.4)$ & $18.7( \pm 0.9)$ & $9.7( \pm 0.5)$ & Kjeldahl method \\
\hline Lipids (wt\% of dry matter) & 14.8 & $5.2( \pm 0.4)$ & $6.0( \pm 0.3)$ & $8.1( \pm 0.6)$ & $\begin{array}{l}\text { Hydrochloric acid digestion }+ \\
\text { Petroleum ether extraction }\end{array}$ \\
\hline Ash content at $550{ }^{\circ} \mathrm{C}$ (wt $\%$ of dry matter) & $4.3( \pm 0.2)$ & $1.2( \pm 0.1)$ & $2.9( \pm 0.2)$ & $4.8( \pm 0.4)$ & NF EN 14775 [19] \\
\hline
\end{tabular}


Fig. 1 Amino acid profile (a) and fatty acid profile (b) of the proteins and lipids contained in blackcurrant pomace
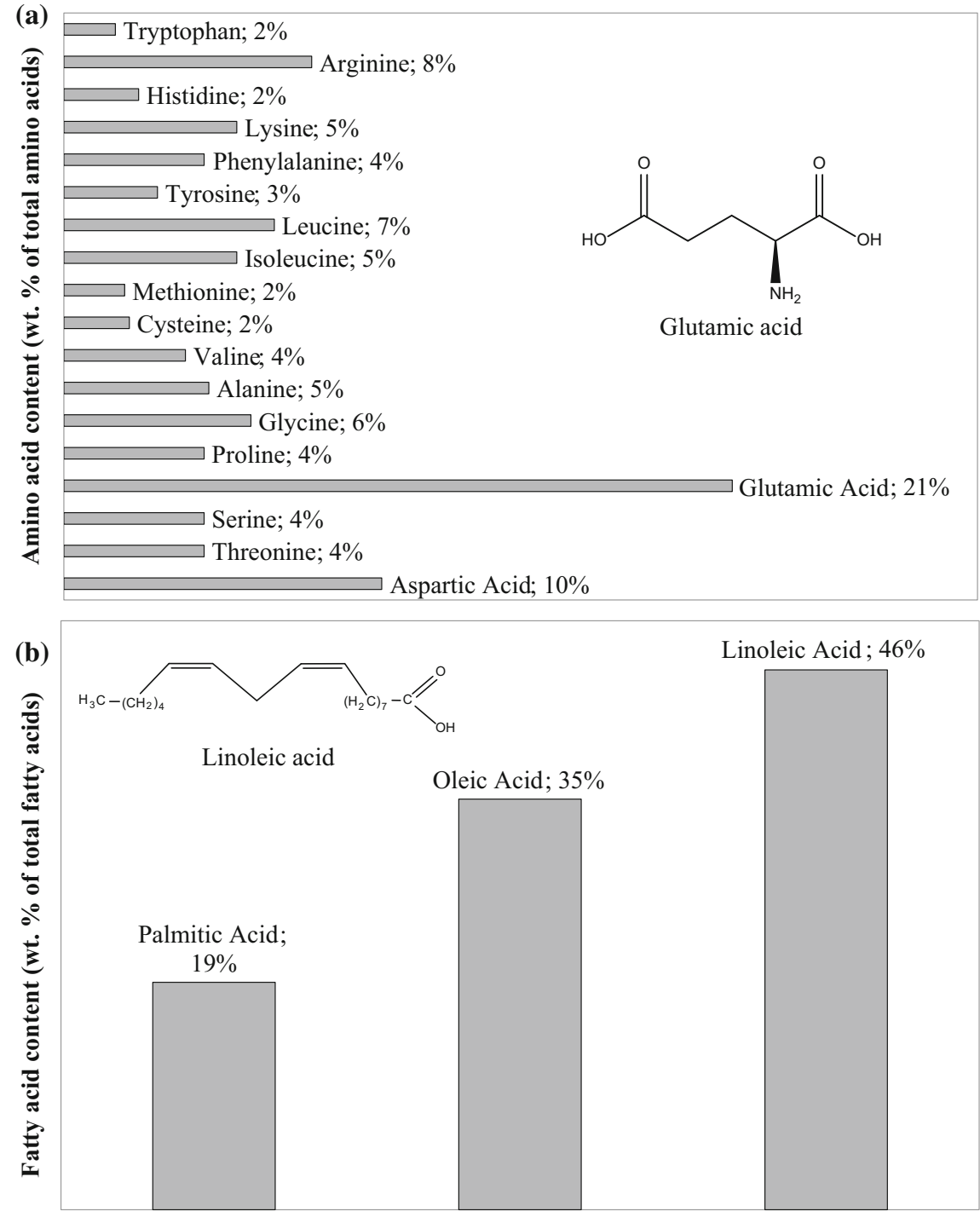

variables are defined as follows: $\mathrm{x}_{1}$ stands for the mass fraction of glucose or cellulose in a model mixture, $x_{2}$ stands for the mass fraction of glutamic acid, $x_{3}$ is the mass fraction of guaiacol or lignin, and $\mathrm{x}_{4}$ stands for the mass fraction of linoleic acid. In Fig. 2, we show a schematic representation of the designs used to perform HTL of model compounds. Table 2 shows the experi mental matrices corresponding to these designs.

\section{Polynomial Regression Models}

Results obtained following the DOEs were exploited using polynomial regression tools, to build correlations describ ing the mass yields as a function of the initial biomass composition. Two models were considered: a linear model and a quadratic model. General expressions of such models are given in Eqs. 1 and 2.
$\mathrm{Y}=\sum_{\mathrm{i} 1}^{\mathrm{q}} \mathrm{b}_{\mathrm{i}} \mathrm{x}_{\mathrm{i}}$

$Y=\sum_{i=1}^{q} b_{i} x_{i}+\sum_{i<j}^{q} b_{i j} x_{i} x_{j}$

where $\mathrm{Y}$ is the experimental response (e.g. mass yield of bio oil); $\mathrm{q}$ is the number of model compounds in the DOE (here, $q=4$ ); $b_{i}$ is the linear contribution coefficient of model compound $i ; \mathrm{x}_{\mathrm{i}}$ is the mass fraction of model com pound $i$ in the mixture or in the biomass; $b_{\mathrm{ij}}$ is the binary interaction coefficient between model compound $i$ and model compound $j ; \mathrm{x}_{\mathrm{j}}$ is the mass fraction of model com pound $j$ in the mixture or in the biomass.

Fitting of the model parameters was done by calculating the correlation coefficient $R^{2}$, targeted at a value of 1 . The significance of correlations was assessed by determining 
(a)

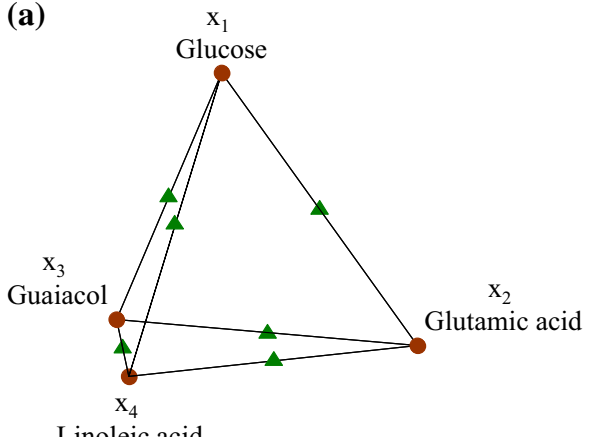

Linoleic acid

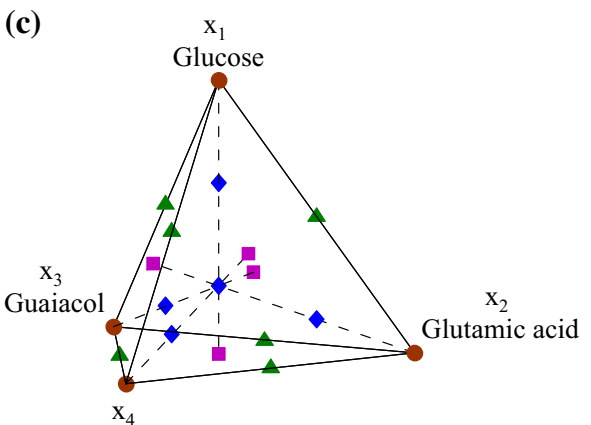

Linoleic acid (b)

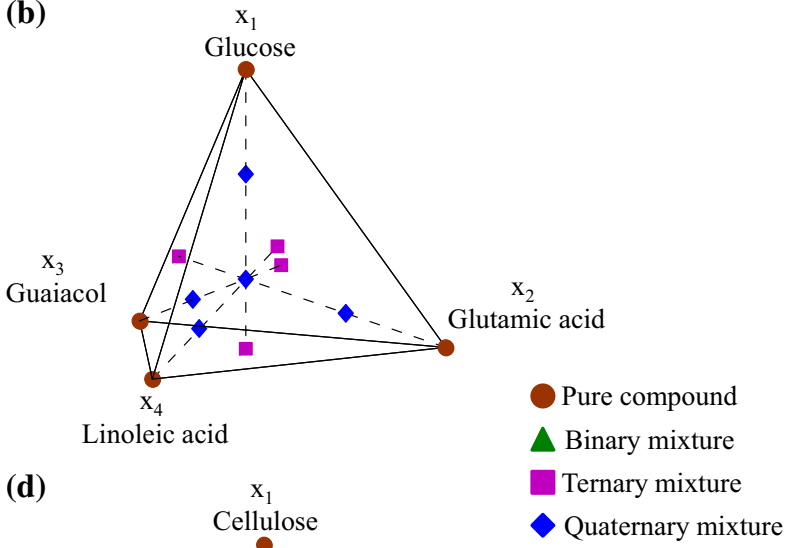

$\mathrm{x}_{3}$

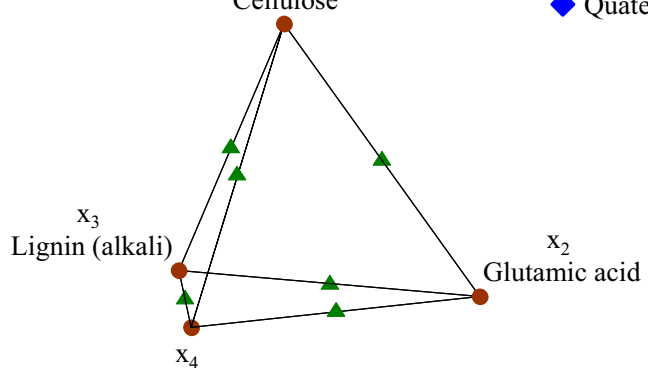

Linoleic acid

Fig. 2 DOE used in HTL of model compounds. a Scheffe design (4,2) with 4 model monomers, b axial design with 4 model monomers, c axial design + binary mixtures with 4 model monomers, and d Scheffe design $(4,2)$ with cellulose and lignin as model compounds for fibers

Table 2 Experimental matrices for HTL of model compounds

\begin{tabular}{llllll}
\hline & Run $\mathrm{N}^{\circ}$ & $\mathrm{x}_{1}$ & $\mathrm{x}_{2}$ & $\mathrm{x}_{3}$ & $\mathrm{x}_{4}$ \\
\hline Pure compounds $^{1,2}$ & $1\left(1^{\prime}\right)$ & 1 & 0 & 0 & 0 \\
& 2 & 0 & 1 & 0 & 0 \\
Binary mixtures $^{1,2}$ & $3\left(3^{\prime}\right)$ & 0 & 0 & 1 & 0 \\
& 4 & 0 & 0 & 0 & 1 \\
& $5\left(5^{\prime}\right)$ & 0.5 & 0.5 & 0 & 0 \\
& $6\left(6^{\prime}\right)$ & 0.5 & 0 & 0.5 & 0 \\
Ternary mixtures $^{2}$ & $7\left(7^{\prime}\right)$ & 0.5 & 0 & 0 & 0.5 \\
& $8\left(8^{\prime}\right)$ & 0 & 0.5 & 0.5 & 0 \\
& 9 & 0 & 0.5 & 0 & 0.5 \\
& $10\left(10^{\prime}\right)$ & 0 & 0 & 0.5 & 0.5 \\
& 11 & 0 & $1 / 3$ & $1 / 3$ & $1 / 3$ \\
& 12 & $1 / 3$ & 0 & $1 / 3$ & $1 / 3$ \\
& 13 & $1 / 3$ & $1 / 3$ & 0 & $1 / 3$ \\
& 14 & $1 / 3$ & $1 / 3$ & $1 / 3$ & 0 \\
& 15 & 0.25 & 0.25 & 0.25 & 0.25 \\
& 16 & 0.625 & 0.125 & 0.125 & 0.125 \\
& 17 & 0.125 & 0.625 & 0.125 & 0.125 \\
& 18 & 0.125 & 0.125 & 0.625 & 0.125 \\
& 19 & 0.125 & 0.125 & 0.125 & 0.625 \\
\hline
\end{tabular}

Runs between parentheses correspond to the use of cellulose and/or lignin instead of glucose and/or guaiacol

$\mathrm{x}_{1}$, glucose and/or cellulose; $\mathrm{x}_{2}$, glutamic acid; $\mathrm{x}_{3}$, guaiacol and/or alkali lignin; $\mathrm{x}_{4}$, linoleic acid

${ }^{1}$ Scheffe design $(4,2)$

${ }^{2}$ Axial mixture design + binary mixtures 
the $p$ value from the Fisher test (Eq. 3), and the signifi cance of the coefficients was assessed by determining the $p$ value from the Student test (Eq. 4), following the rec ommendations of Tinsson [22].

$\mathrm{F}=\frac{\mathrm{n}-\mathrm{p}}{\mathrm{p}-1} \cdot \frac{\sum_{\mathrm{k} 1}^{\mathrm{n}}\left(\hat{\mathrm{y}}_{\mathrm{k}}-\overline{\mathrm{y}}\right)^{2}}{\sum_{\mathrm{k} 1}^{\mathrm{n}}\left(\mathrm{y}_{\mathrm{k}}-\hat{\mathrm{y}}_{\mathrm{k}}\right)^{2}}$

$\mathrm{t}=\frac{\mathrm{b}_{\mathrm{i}}\left(\text { or }_{\mathrm{ij}}\right)}{\mathrm{SD}_{\mathrm{b}_{\mathrm{i}}\left(\text { or }_{\mathrm{ij}}\right)}}$

where $\mathrm{F}$ is the value of the $F$ test; $\mathrm{n}$ is the total number of experiments; $p$ is the number of parameters of the model ( $\mathrm{p}=4$ for the linear model, $\mathrm{p}=10$ for the quadratic model); $\hat{y}_{k}$ is the calculated experimental response for experiment $\mathrm{k}$; $\overline{\mathrm{y}}$ is the mean value of the experimental responses; $y_{k}$ is the measured experimental response for experiment $\mathrm{k} ; \mathrm{t}$ is the value of the student test; $b_{i}$ is the linear contribution coefficient of model compound $i$; $\mathrm{b}_{\mathrm{ij}}$ is the binary interaction coefficient between model compound $i$ and model compound $j$; $\mathrm{SD}_{\mathrm{bi} \text { (or bij) }}$ is the standard devi ation on the contribution coefficient $b_{i}\left(\right.$ or $\left.b_{i j}\right)$.

The validity of the correlations was then evaluated by comparison with the results of hydrothermal liquefaction of two model mixtures and four real food processing residues: blackcurrant pomace, raspberry achenes, brew er's spent grains and grape marc. A mass averaged model was also tested (Eq. 5), as suggested in previous studies $[12,14,15]$.
$\mathrm{Y}=\sum_{\mathrm{i}=1}^{\mathrm{q}} \mathrm{Y}_{\mathrm{i}} \mathrm{X}_{\mathrm{i}}$

where $\mathrm{Y}$ is the experimental response (e.g. mass yield of bio oil); $q$ is the number of model compounds in the DOE (here, $\mathrm{q}=4$ ); $\mathrm{Y}_{\mathrm{i}}$ is the experimental response of a single model compound $i$ (e.g. mass yield of bio oil for compound $i) ; \mathrm{x}_{\mathrm{i}}$ is the mass fraction of model compound $i$ in the mixture or in the biomass.

\section{Hydrothermal Liquefaction}

\section{HTL Experiments}

Hydrothermal liquefaction experiments were performed in a $0.6 \mathrm{~L}$ stainless steel (type 316) stirred batch reactor (Parr Instruments). In a typical experiment, the reactor was filled with approximately $240 \mathrm{~g}$ of slurry prepared from either model compounds, model mixtures or real food processing residues. A constant concentration of $15 \mathrm{wt} \%$ dry matter in the reaction slurry was used. Figure 3 shows the experi mental procedure for HTL experiments and recovery of products. Before running an experiment, the autoclave was leak tested, purged and pressurized to $1 \mathrm{MPa}$ with nitrogen gas to guarantee sufficient pressure for gas analysis after the reaction. The reactor was then heated from room temperature to the reaction temperature $\left(300^{\circ} \mathrm{C}\right)$ in about $3035 \mathrm{~min}$. Once the reactor reached the reaction temperature, it was
Fig. 3 Experimental procedure for HTL experiments and recovery of products

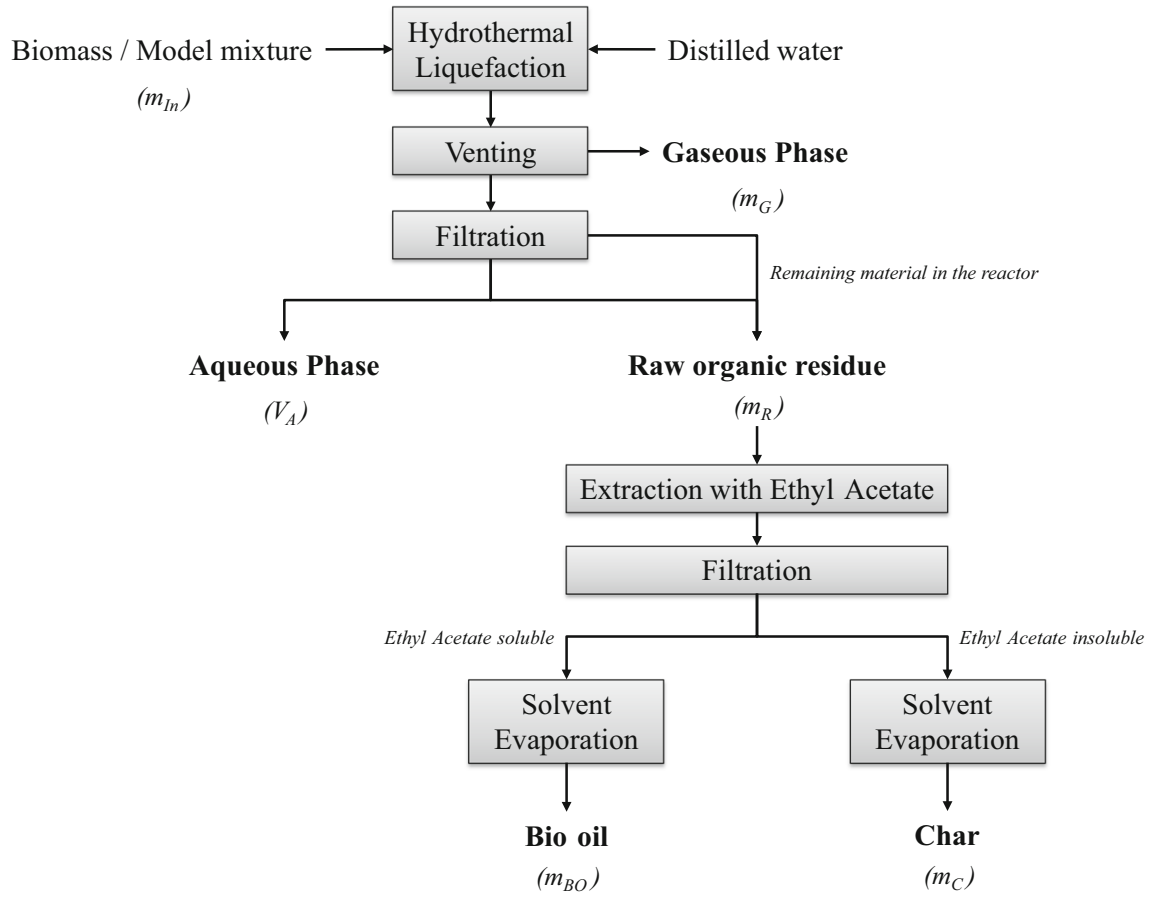


held during a 60 min holding time within $\pm 1{ }^{\circ} \mathrm{C}$ of the reaction temperature. The reaction was performed at a stir ring speed of $600 \mathrm{rpm}$. After the holding time, the reactor was rapidly cooled down to room temperature in $20 \mathrm{~min}$ by an air quench. The gas in the reactor was vented and analyzed by a micro chromatograph (Varian Quad CP 4900) equipped with a thermal conductivity detector used on line. Permanent gases $\left(\mathrm{O}_{2}, \mathrm{H}_{2}, \mathrm{CO}\right.$ and $\left.\mathrm{CH}_{4}\right)$ were separated by a molecular sieve column using argon as carrier gas. Light hydrocarbons $\left(\mathrm{C}_{2} \mathrm{H}_{4}, \mathrm{C}_{2} \mathrm{H}_{6}, \mathrm{C}_{2} \mathrm{H}_{2}\right.$ and $\left.\mathrm{C}_{3} \mathrm{H}_{8}\right), \mathrm{CO}_{2}$ and sulphur species $\left(\mathrm{H}_{2} \mathrm{~S}\right.$ and $\mathrm{COS}$ ) were separated on a Poraplot $\mathrm{U}$ column using helium as carrier gas. Solid and liquid products were then recovered and analyzed following the recovery procedure described in "Recovery of Products" section.

\section{Recovery of Products}

After gas analysis, the reactor was opened and the products were recovered following the procedure given in Fig. 3. The content of the reactor was first filtered on a Buchner filter to separate the aqueous phase from the raw organic residue. The raw organic residue was recovered as a hydrophobic solid liquid mixture containing bio oil and char. In most experiments, the raw organic residue was easily separated from the aqueous phase by filtration. The aqueous phase would pass through the filter while the raw organic residue would stay on the filter. The bio oil and the char are intimately associated and remain on the filter. In some experiments, only an aqueous phase and an organic phase (bio oil) were recovered (no char): in these specific cases, the bio oil was separated from the aqueous phase using a separatory funnel. As shown in Fig. 3, the remaining material in the reactor was counted as raw organic residue (wet). Moisture content of the raw organic residue $\left(\mathrm{W}_{\mathrm{R}}\right)$ was estimated using two methods: drying at room temperature under air circulation until a stable mass was obtained, and Karl Fischer titration using a Schott Instruments Titroline KF. Combination of the two methods allows evaluating the experimental error due to estimation of the moisture content of the raw organic residue. The difference is partly due to the evaporation of some volatile compounds.

The raw organic residue was then extracted using a tenfold amount of ethyl acetate (w/w) to separate the bio oil from the char on a Buchner filter. Ethyl acetate was chosen because it allows good bio oil recovery [23], is non toxic, and has a low miscibility with water. Bio oil was recovered after evaporation of ethyl acetate at room tem perature under air circulation until a stable mass was obtained. The char was also dried at room temperature under air circulation until a stable mass was obtained. Weight loss of the char after extraction and drying was used to determine the proportion of solvent soluble organics in the raw organic residue (SSO), and therefore the bio oil yield $\left(\mathrm{Y}_{\mathrm{BO}}\right)$. Calculation of the yields is explained in "Calculation of the Mass Yields" section.

\section{Calculation of the Mass Yields}

Yields were calculated from the obtained experimental results. They are defined as the mass ratios between the recovered phases and the dry biomass used in the experiment. The bio oil $\left(\mathrm{Y}_{\mathrm{BO}}\right)$ and char $\left(\mathrm{Y}_{\mathrm{C}}\right)$ yields were calculated using the results from solvent extraction (Eqs. 6 and 7).

$$
\begin{aligned}
& \mathrm{Y}_{\mathrm{BO}}=\frac{\mathrm{m}_{\mathrm{BO}}}{\mathrm{m}_{\text {In }}}=\frac{\mathrm{m}_{\mathrm{R}} \cdot\left(\mathrm{SSO}-\mathrm{W}_{\mathrm{R}}\right)}{\mathrm{m}_{\text {In }}} \\
& \mathrm{Y}_{\mathrm{C}}=\frac{\mathrm{m}_{\mathrm{C}}}{\mathrm{m}_{\mathrm{In}}}=\frac{\mathrm{m}_{\mathrm{R}} \cdot(1-\mathrm{SSO})}{\mathrm{m}_{\text {In }}}
\end{aligned}
$$

where $\mathrm{Y}_{\mathrm{BO}}$ and $\mathrm{Y}_{\mathrm{C}}$ are the bio oil and char yields (wt\% of initial dry ash free matter), respectively; $\mathrm{m}_{\mathrm{BO}}, \mathrm{m}_{\mathrm{C}}, \mathrm{m}_{\mathrm{In}}$ and $\mathrm{m}_{\mathrm{R}}$ are the mass of bio oil, char, initial dry ash free matter and raw organic residue ( $\mathrm{g}$ ), respectively; SSO is the pro portion of solvent soluble organics in the raw organic residue (wt $\%$ ) and $\mathrm{W}_{\mathrm{R}}$ is the water content of the raw organic residue (wt\%).

The gas yield $\left(\mathrm{Y}_{\mathrm{G}}\right)$ was calculated by initial and final temperatures and pressures measurements using the ideal gas law, and the composition of the gas phase obtained by micro chromatography (Eqs. 8 and 9).

$\mathrm{m}_{\mathrm{G}}=\frac{\mathrm{V}_{\mathrm{G}}}{\mathrm{R}} \cdot\left(\frac{\mathrm{P}_{\mathrm{f}}}{\mathrm{T}_{\mathrm{f}}}-\frac{\mathrm{P}_{\mathrm{i}}}{\mathrm{T}_{\mathrm{i}}}\right) \cdot \sum_{\mathrm{j}} \mathrm{M}_{\mathrm{j}} \cdot \mathrm{y}_{\mathrm{j}}$

$\mathrm{Y}_{\mathrm{G}}=\frac{\mathrm{m}_{\mathrm{G}}}{\mathrm{m}_{\mathrm{In}}}$

where $\mathrm{m}_{\mathrm{G}}$ is the mass of gas formed during an experiment $(\mathrm{g}) ; \mathrm{V}_{\mathrm{G}}$ is the volume of gaseous phase in the reactor $\left(\mathrm{m}^{3}\right)$; $\mathrm{R}$ is the ideal gas constant $\left(8.314 \mathrm{~J} \mathrm{~K}^{-1} \mathrm{~mol}^{-1}\right) ; \mathrm{P}_{\mathrm{f}}$ and $\mathrm{P}_{\mathrm{i}}$ are respectively the final and initial pressures in the reactor $(\mathrm{Pa}) ; \mathrm{T}_{\mathrm{f}}$ and $\mathrm{T}_{\mathrm{i}}$ are respectively the final and initial tem peratures in the reactor $(\mathrm{K}) ; \mathrm{M}_{\mathrm{j}}$ is the molar mass of gas eous species $j\left(\mathrm{~g} \mathrm{~mol}^{-1}\right) ; \mathrm{y}_{\mathrm{j}}$ is the molar fraction of gaseous species $j, \mathrm{Y}_{\mathrm{G}}$ is the gas yield (wt \% of initial dry ash free matter) and $m_{\text {In }}$ is the initial dry ash free matter $(\mathrm{g})$.

In the results and discussion section, we report the yield of organic matter in aqueous phase $\left(\mathrm{Y}_{\mathrm{A}}\right)$. The aqueous phase yields $\left(\mathrm{Y}_{\mathrm{A}}\right)$ was calculated by difference (Eq. 10). These yields should be considered as indicative values, as the overall organic mass balance does not necessarily close to $100 \%$, because of hydration and dehydration reactions involving water as either a catalyst or a reactant.

$\mathrm{Y}_{\mathrm{A}}=1-\mathrm{Y}_{\mathrm{BO}}-\mathrm{Y}_{\mathrm{C}}-\mathrm{Y}_{\mathrm{G}}$ 
In the results and discussion section, experimental val ues are the mean values of two replicates of each experi ment. Error bars are the standard deviations.

\section{Results and Discussion}

\section{Assessment of the Representativeness of Model Mixtures Towards HTL of Blackcurrant Pomace}

\section{Composition of the Model Mixtures}

Hydrothermal liquefaction of two different model mix tures was conducted to assess the representativeness of model molecules towards HTL of blackcurrant pomace, based on the comparison between mass yields of the products. Table 3 reports the composition of the two model mixtures used for the comparison, based on the composition of blackcurrant pomace shown in Table 1 . Note that the carbohydrate content (cellulose hemicellu loses sugars, corresponding to the $\mathrm{x}_{1}$ variable in the DOEs) is calculated as the difference between $100 \%$ and the sum of lignin, protein and lipid contents. Although some other components may be integrated in this fraction, it gives a good estimate of the carbohydrate fraction of the biomass.

The above mixtures only differ by the model molecules used to represent the fiber content of blackcurrant pomace. Either only model monomers are used (mixture 1), or exclusively model polymers (mixture 2 ). We made this choice because the biopolymers constituting the fibers of biomass have been identified before as high contributors to the char yield during hydrothermal liquefaction [24].

\section{Comparison of the Mass Yields}

We show in Fig. 4 the comparison between the experi mental mass yields obtained by HTL of blackcurrant pomace and HTL of the model mixtures. The results show a great variation in the products distribution. A better representativeness of mixture 2 is observed towards the real case of blackcurrant pomace.

Bio oil yields are slightly overestimated in the case of mixture 1 and mixture 2, respectively by $7 \mathrm{wt} \%$ and $1 \mathrm{wt} \%$, compared to the experimental yields obtained with blackcurrant pomace. Char yields are at the same time underestimated by $23 \mathrm{wt} \%$ (mixture 1) and $12 \mathrm{wt} \%$ (mix ture 2). In terms of char yields, the most representative model mixture is the one using polymers as model com pounds for the native fiber content of blackcurrant pomace, indicating a strong contribution of these compounds to the formation of solid residue during HTL. From the results, two different contributions to the char yield can be iden tified: the first one corresponds to an incomplete hydrolysis of the fibers, while the second one is due to recombination of reactive intermediates (model monomers and subsequent degradation products). This is what is illustrated by the higher char yield obtained in mixture 2, compared to mixture 1 . When only model monomers are used (mixture 1), the char yield is lower because it simulates an "ideal" case, in which the fibers are already totally hydrolyzed and model monomers totally available for subsequent reactions. On the other hand, incomplete hydrolysis of the fibrous polymers in the case of mixture 2 leads to a higher amount of char. Finally, the lower char yield compared to black currant pomace can be explained by the fact that fibers are not linked to each other in model mixtures, contrarily to real biomass.
Table 3 Composition of the model mixtures used for comparison with HTL of blackcurrant pomace (wt $\%$ daf)

\begin{tabular}{|c|c|c|c|}
\hline Model compound & Blackcurrant pomace & $\begin{array}{l}\text { Mixture } 1 \\
\text { (monomers only) }\end{array}$ & $\begin{array}{l}\text { Mixture } 2 \\
\text { (monomers and polymers) }\end{array}$ \\
\hline Cellulose hemicelluloses sugars & $30.6^{\mathrm{a}}$ & & \\
\hline Glucose & & 30.7 & \\
\hline Microcrystalline cellulose & & & 30.6 \\
\hline Lignin & 36.2 & & \\
\hline Guaiacol & & 36.3 & \\
\hline Lignin (alkali) & & & 36.3 \\
\hline Proteins & 17.7 & & \\
\hline Glutamic acid & & 17.6 & 17.8 \\
\hline Lipids & 15.5 & & \\
\hline Linoleic acid & & 15.4 & 15.4 \\
\hline
\end{tabular}

${ }^{a}$ Calculated by difference from the data presented in Table 1 


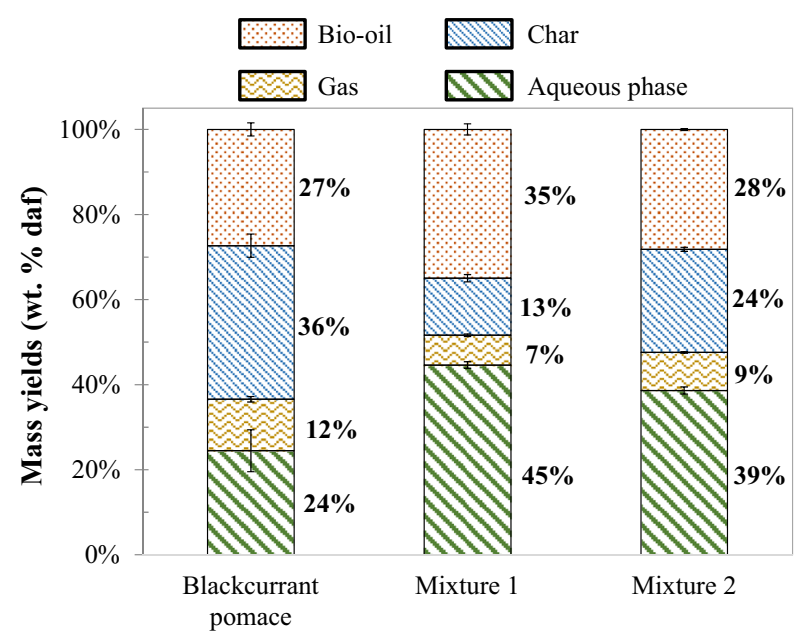

Fig. 4 Comparison of experimental mass yields from HTL of blackcurrant pomace and two model mixtures

Higher gas yield and closer estimation of the real case is obtained when using polymers (mixture 2) instead of monomers (mixture 1) as model molecules for the fibers. This indicates the occurrence of direct gas formation from polymer degradation, leading to a higher amount of gas. Yet, gas yields are still underestimated in the case of model mixtures, which could result from the absence of inorganics in the model mixtures: inorganic salts have been identified before as influencing the gas formation pathways [25].
Finally HTL of model mixtures leads to a higher aqueous phase yield, mainly because of the lower yields of other products. Therefore, the overall comparison of the results shows that the most representative model mixture is the one using model polymers as representatives for fibers. Mixture 2, using exclusively model polymers for the fiber content of blackcurrant pomace, seems to be the most representative when compared with the real case. Some differences are still observed, as discussed above, mainly because of the nature of the model molecules. In the next section, we present the experimental results obtained by hydrothermal conversion of the model compounds, fol lowing the DOEs presented in "Design of Experiments" section.

\section{Hydrothermal Conversion of Model Monomers}

\section{Results of HTL Experiments}

Hydrothermal conversion of model monomers was con ducted for pure model compounds, as well as model mix tures of two to four compounds, following the mixtures designs described in Table 2. We report in Table 4 the results of the experiments.

Experiments on pure model compounds show that the smallest contributors to the bio oil yield are glucose (run 1) and glutamic acid (run 2). While glucose degrades to form mainly char and water soluble organics, glutamic acid reacts to produce mainly water soluble organics and a

Table 4 Experimental yields from HTL of model monomers (wt $\%$ of initial dry ash free matter)

\begin{tabular}{|c|c|c|c|c|c|}
\hline Run $\mathrm{N}^{\circ}$ & Model compounds & Bio oil & Char & Gas & Aqueous phase \\
\hline 1 & Glucose & $6.4( \pm 2.4)$ & $40.0( \pm 0.1)$ & $8.3( \pm 0.7)$ & $45.3( \pm 2.0)$ \\
\hline 2 & Glutamic acid & $0.0( \pm 0.0)$ & $0.0( \pm 0.0)$ & $4.9( \pm 0.4)$ & $95.1( \pm 0.4)$ \\
\hline 3 & Guaiacol & $71.1( \pm 11.3)$ & $0.0( \pm 0.0)$ & $0.0( \pm 0.0)$ & $28.9( \pm 11.2)$ \\
\hline 4 & Linoleic acid & $95.0( \pm 2.5)$ & $0.0( \pm 0.0)$ & $0.2( \pm 0.2)$ & $4.8( \pm 2.3)$ \\
\hline 5 & Glucose glutamic acid & $12.7( \pm 1.2)$ & $24.6( \pm 6.6)$ & $12.8( \pm 0.2)$ & $49.9( \pm 5.2)$ \\
\hline 6 & Glucose guaiacol & $27.3( \pm 0.0)$ & $35.4( \pm 0.0)$ & $3.8( \pm 0.0)$ & $33.6( \pm 0.0)$ \\
\hline 7 & Glucose linoleic acid & $62.7( \pm 0.0)$ & $9.9( \pm 0.0)$ & $3.8( \pm 0.0)$ & $23.6( \pm 0.0)$ \\
\hline 8 & Glutamic acid guaiacol & $21.4( \pm 0.0)$ & $0.0( \pm 0.0)$ & $1.3( \pm 0.0)$ & $77.3( \pm 0.0)$ \\
\hline 9 & Glutamic acid linoleic acid & $58.6( \pm 2.7)$ & $0.0( \pm 0.0)$ & $1.9( \pm 0.1)$ & $39.5( \pm 2.8)$ \\
\hline 10 & Guaiacol linoleic acid & $76.0( \pm 7.6)$ & $0.0( \pm 0.0)$ & $0.0( \pm 0.0)$ & $24.0( \pm 7.6)$ \\
\hline 11 & Glucose glutamic acid guaiacol & $29.0( \pm 2.0)$ & $10.2( \pm 0.0)$ & $8.2( \pm 0.0)$ & $52.6( \pm 2.0)$ \\
\hline 12 & Glucose glutamic acid linoleic acid & $43.5( \pm 1.8)$ & $13.5( \pm 0.0)$ & $8.7( \pm 0.0)$ & $34.3( \pm 1.8)$ \\
\hline 13 & Glucose guaiacol linoleic acid & $51.9( \pm 0.0)$ & $0.0( \pm 0.0)$ & $2.6( \pm 0.0)$ & $45.5( \pm 0.0)$ \\
\hline 14 & Glutamic acid guaiacol linoleic acid & $59.7( \pm 0.0)$ & $0.0( \pm 0.0)$ & $0.6( \pm 0.0)$ & $39.7( \pm 0.0)$ \\
\hline 15 & Quaternary mixture (25\% each) & $44.8( \pm 3.8)$ & $7.9( \pm 0.0)$ & $7.1( \pm 0.0)$ & $40.2( \pm 3.8)$ \\
\hline 16 & $62.5 \%$ Glucose $12.5 \%$ others & $24.6( \pm 5.7)$ & $32.0( \pm 0.0)$ & $7.1( \pm 0.0)$ & $36.2( \pm 5.7)$ \\
\hline 17 & $62.5 \%$ Glutamic acid $12.5 \%$ others & $25.8( \pm 0.0)$ & $4.1( \pm 0.0)$ & $7.6( \pm 0.0)$ & $62.5( \pm 0.0)$ \\
\hline 18 & $62.5 \%$ Guaiacol $12.5 \%$ others & $85.7( \pm 0.0)$ & $0.6( \pm 0.0)$ & $3.7( \pm 0.0)$ & $10.0( \pm 0.0)$ \\
\hline 19 & $62.5 \%$ Linoleic acid $12.5 \%$ others & $70.2( \pm 0.0)$ & $0.9( \pm 0.0)$ & $0.5( \pm 0.0)$ & $28.5( \pm 0.0)$ \\
\hline
\end{tabular}



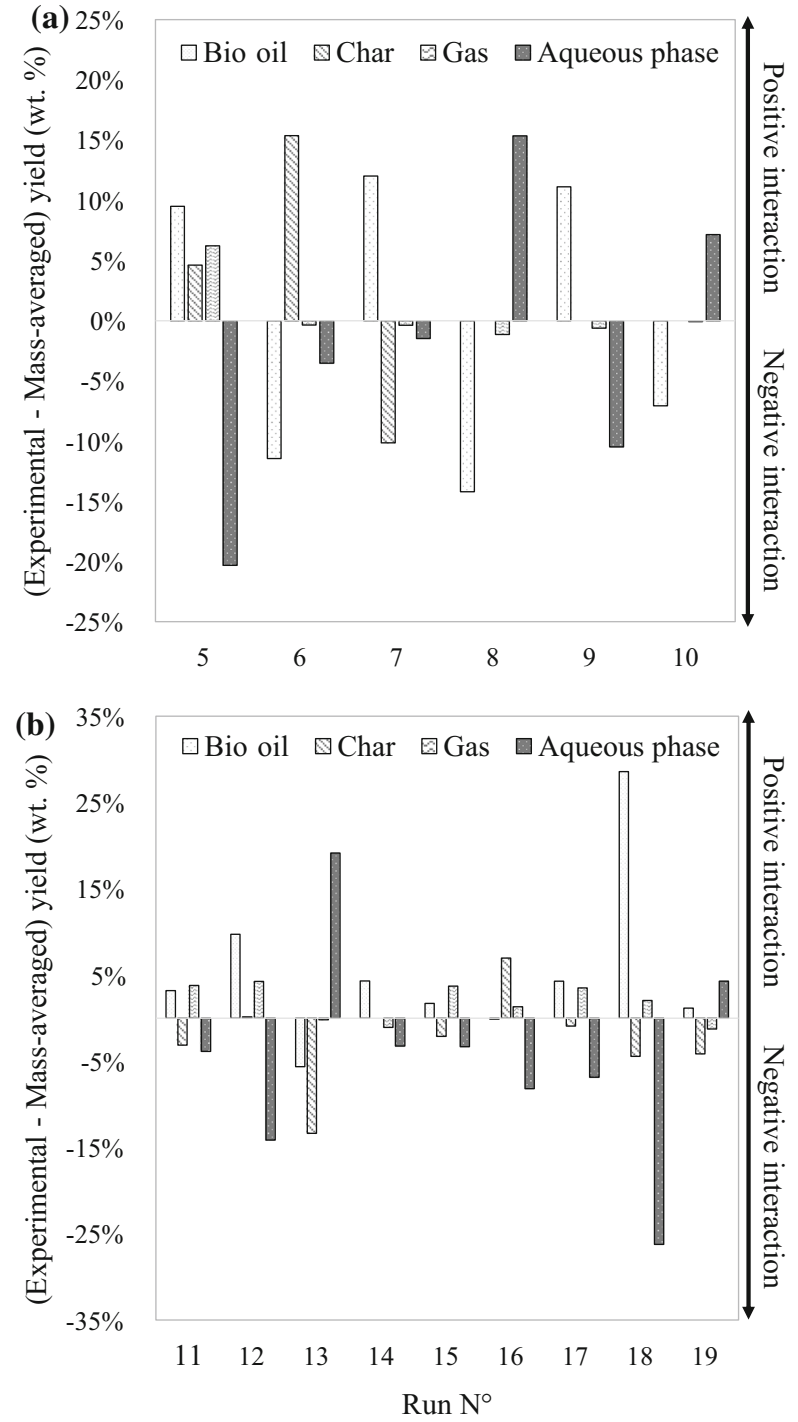

Fig. 5 Comparison between experimental and mass averaged calcu lated yields from HTL of a binary mixtures, and b ternary and quaternary mixtures of model monomers

small amount of gas. On the other hand, guaiacol and linoleic acid contribute significantly to the bio oil yield. These results are in line with previous works from the literature, which identified lipids to be the main contribu tors to the bio oil yield $[12,13]$. Contrarily to what has been observed with model proteins (polymers) in previous works, the conversion of a single amino acid alone (monomer) does not lead to bio oil in this work. In the case of model monomers, char formation is mainly the results of repolymerization reactions from the intermediates pro duced by glucose degradation, as evidenced by the fact that solid residue was only recovered when glucose was ini tially present in the reaction medium.
In Fig. 5, potential positive or negative interactions in model mixtures are identified by comparing experimental yields with mass averaged yields, calculated from the mass yields obtained with individual model compounds (Eq. 5). When the experimental yield is higher than the mass av eraged one, a positive interaction is identified.

In the case of binary mixtures, the comparison between mass averaged yields and experimental results allows iden tifying positive interactions for formation of some products. This is especially the case for the glucose glutamic acid binary mixture (run 5), which produces higher bio oil, char and gas yields than their respective individual model monomers. This means that model monomers and their degradation products take part in interaction reactions, increasing the formation of some products. In particular, the increase of the bio oil yields can be explained by Maillard type reactions, producing nitrogen heterocycles [15]. Yang et al. [15] also reported a strong beneficial effect of carbo hydrate protein interaction for the bio oil formation at $300{ }^{\circ} \mathrm{C}$. Maillard type reactions produce polymeric mela noidins that decompose to generate nitrogenous heterocy cles. Another positive interaction towards bio oil formation seem to arise from the glucose linoleic acid binary mixture (run 7). When compared to the case of pure glucose, hydrothermal conversion of this mixture results in a 4 fold reduction of the char amount. In addition, the bio oil yield is higher than $50 \mathrm{wt} \%$ in the case of the binary mixture, sug gesting a positive interaction for bio oil formation. There fore, the bio oil yield seems to benefit from the interaction between glucose and linoleic acid, because of the inhibition of char formation from bio oil repolymerization. Similarly, the glutamic acid linoleic acid binary mixture (run 9) pro duces a bio oil yield higher than the mass averaged yield calculated from individual model compounds, indicating that certain interactions occur, probably through formation of long chain amides [26].

Experimental yields suggest that positive interactions for char formation occur during hydrothermal conversion of the glucose guaiacol binary mixture (run 6). In fact, using twice less glucose in the initial mixture does not result in a twofold reduction of the char yield, but in a comparable char yield to the case of glucose converted alone. The bio oil yield is at the same time reduced 3 fold compared to the case of pure guaiacol. This indicates that glucose, guaiacol and their respective degradation compounds may interact via con densation pathways to form char. Finally, another observ able interaction is an increased solubilization of organic matter in the aqueous phase in the case of the glutamic acid guaiacol (run 8) and guaiacol linoleic acid binary mixtures (run 10), at the expense of the bio oil yields.

The results of hydrothermal conversion of ternary and quaternary mixtures are in good agreement with the results from the individual model compounds and binary mixtures. 
For instance, a glucose rich mixture (run 16) leads to more char formation, while a linoleic acid rich mixture (run 19) produces more bio oil. Overall, when comparing experi mental data to calculated mass averaged yields from indi vidual model compounds, results show that the products result both from individual model compounds degradation and interactions.

\section{Correlating the Mass Yields by Polynomial Regression}

From the above results, polynomial regression models were used to establish correlations describing the mass yields as a function of the starting composition of the biomass. Three different designs of experiments (simplex lattice, axial and axial + binary mixtures) and two different models (linear and quadratic) led to the building of 6 correlations for each mass yield. We report in Table S1 of the electronic supplementary material the calculated coef ficients for each correlation, as well as the corresponding correlation coefficients. The correlations are named according to the used DOE ( 1 for Scheffe design, 2 for axial design and 3 for axial + binary mixtures design), the product phase ( $b$ for bio oil, $c$ for char, $g$ for gas, and $a$ for aqueous phase) and the regression model used ( $l$ for linear, $q$ for quadratic).

Linear coefficients corresponding to the contribution of individual model compounds only differ slightly from one correlation to the other. They confirm the observations made in "Results of HTL Experiments" section on the contribution of individual model compounds on the for mation of products. For instance, guaiacol and linoleic acid are the major contributors to the bio oil yield. Especially, the linear coefficients corresponding to the lipid contribu tion are very close to those previously determined in the literature, over 0.95 . This confirms the high contribution of lipids to the bio oil, and the advantage of using subcritical water to separate the lipid content from the biomass $[14,16]$. Higher variability is observed in the calculated coefficients for the binary interaction terms. Especially, most binary coefficients calculated using the axial design and the quadratic regression model (correlations $2 b, q, 2 c, q$, $2 g, q$ and $2 a, q$ ) are not in agreement with the observations made in Fig. 5 about binary interactions between model monomers. For instance, the coefficient $b_{14}$ (glucose li noleic acid binary interaction) is negative in correlation $2 b, q$, while a positive interaction was identified in Fig. 5. This is most likely due to the fact that binary mixtures are excluded from this particular DOE, leading to bad esti mation of binary interactions. Evaluating the significance of the coefficients for these correlations confirms this observation, as no quadratic coefficient is considered as significant by the Student test (Table S2 of the electronic supplementary material). Other coefficients are generally in agreement with observations made in "Results of HTL Experiments" section. Correlation coefficients $\mathrm{R}^{2}$ are rel atively good $(0.780 .996)$, meaning that the correlations fit the experimental results. In addition, $F$ tests result in very low $p$ values, showing a good significance of the models (Table S2 and S3 of the electronic supplementary mate rial). As shown in the electronic supplementary material, correlation coefficients are generally better for the quad ratic correlations, which is in agreement with product formation pathways both from individual compound degradation and interaction phenomena. In "Tests and Validation of Correlations" section, the validity of the correlations is tested against experimental results of model mixtures and real resources.

\section{Hydrothermal Conversion of Model Monomers and Polymers}

\section{Results of HTL Experiments}

In this set of experiments, microcrystalline cellulose and alkali lignin were used as model compounds for fibers, respectively instead of glucose and guaiacol. Hydrothermal conversion experiments were conducted following the
Table 5 Experimental yields from HTL of model monomers and polymers for fibers (wt $\%$ of initial dry ash free matter)

\begin{tabular}{|c|c|c|c|c|c|}
\hline Run $\mathrm{N}^{\circ}$ & Model compounds & Bio oil & Char & Gas & Aqueous phase \\
\hline $1^{\prime}$ & Cellulose & $5.6( \pm 1.9)$ & $40.9( \pm 0.6)$ & $10.3( \pm 0.2)$ & $43.3( \pm 1.6)$ \\
\hline 2 & Glutamic acid & $0.0( \pm 0.0)$ & $0.0( \pm 0.0)$ & $4.9( \pm 0.4)$ & $95.1( \pm 0.4)$ \\
\hline $3^{\prime}$ & Lignin (alkali) & $0.1( \pm 0.1)$ & $61.6( \pm 2.3)$ & $4.1( \pm 0.3)$ & $34.2( \pm 2.3)$ \\
\hline 4 & Linoleic acid & $95.0( \pm 2.5)$ & $0.0( \pm 0.0)$ & $0.2( \pm 0.2)$ & $4.8( \pm 2.3)$ \\
\hline $5^{\prime}$ & Cellulose glutamic acid & $7.3( \pm 3.1)$ & $22.9( \pm 3.8)$ & $15.5( \pm 0.3)$ & $54.3( \pm 0.8)$ \\
\hline $6^{\prime}$ & Cellulose lignin (alkali) & $22.5( \pm 1.5)$ & $24.2( \pm 0.7)$ & $11.1( \pm 0.1)$ & $42.2( \pm 2.2)$ \\
\hline $7^{\prime}$ & Cellulose linoleic acid & $61.6( \pm 1.6)$ & $10.2( \pm 1.3)$ & $4.5( \pm 0.2)$ & $23.7( \pm 1.8)$ \\
\hline $8^{\prime}$ & Glutamic acid lignin (alkali) & $5.7( \pm 1.8)$ & $31.3( \pm 0.2)$ & $8.6( \pm 0.1)$ & $54.4( \pm 1.8)$ \\
\hline 9 & Glutamic acid linoleic acid & $58.6( \pm 2.7)$ & $0.0( \pm 0.0)$ & $1.9( \pm 0.1)$ & $39.5( \pm 2.8)$ \\
\hline $10^{\prime}$ & Lignin (alkali) linoleic acid & $40.2( \pm 2.8)$ & $38.9( \pm 3.3)$ & $2.4( \pm 0.3)$ & $18.5( \pm 6.1)$ \\
\hline
\end{tabular}




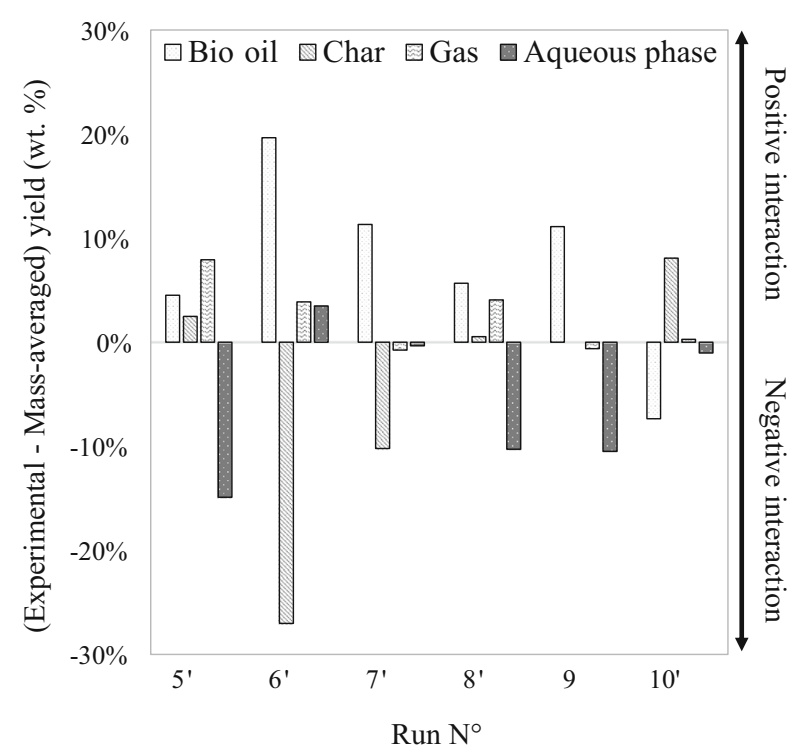

Fig. 6 Comparison between experimental and mass averaged calcu lated yields from HTL of binary mixtures of model monomers and polymers

Scheffe design $(4,2)$ described in Table 2. In Table 5, we report the results of the experiments.

From the results, it can be seen that cellulose behaves in a very similar way to glucose in hydrothermal conditions, while producing higher gas yield. This was also observed by Biller and Ross [12] when comparing HTL of glucose and starch at $350{ }^{\circ} \mathrm{C}$. The higher amount of gas in the case of cellulose indicates that direct gas formation from cel lulose decomposition occurred in the experiments. On the contrary, lignin shows a very different behavior compared to guaiacol. Nearly no bio oil is recovered from HTL of lignin, while it produces a great amount of char, some gas and water soluble organics. These observations underline the resistance of lignin to hydrolysis in the conditions of the study, as well as it shows the occurrence of direct gas formation from lignin.

In Fig. 6, experimental yields obtained from HTL of binary mixtures are compared with calculated mass aver aged yields. From the comparison, it is observed that most interactions benefit to the bio oil phase, at the expense of the char and aqueous phase. Especially, the bio oil yield seem to be highly favored in the case of a cellulose lignin binary mixture (run $6^{\prime}$ ), contrarily to what was observed in the case of a glucose guaiacol binary mixture (run 6). This could be the result of the basic nature of the lignin used in this study (alkali lignin): in fact, HTL of cellulose in basic medium highly benefits to the bio oil yield, at the expense of char formation [27]. Compared to the observations made on model monomers (Fig. 5), differences only arise in the case of the mixtures involving lignin (runs $6^{\prime}, 8^{\prime}$ and $10^{\prime}$ ).

\section{Correlating the Mass Yields by Polynomial Regression}

From the above results presented in Table 5, polynomial regression models were used to establish correlations describing the mass yields starting from the initial bio chemical content of the biomass. In this case, only one DOE was used (simplex lattice design: Scheffe $(4,2)$ ), and two different regression models (linear and quadratic). This led to the building of 2 correlations for each mass yield. We report in Table S2 of the electronic supplementary material the calculated coefficients for each correlation, as well as the corresponding correlation coefficients. Corre lations are named in the same way as previously described in "Correlating the Mass Yields by Polynomial Regres sion" section. As it was the case with model monomers, the calculated coefficients for linear contributions of individual model compounds are very similar for a given yield. Interaction coefficients also show a good agreement with the interactions that arise from Fig. 6. Correlation coeffi cients $\mathrm{R}^{2}$ are relatively good $(0.750 .998)$, showing a good fit of the correlations to the experimental results. In addi tion, $F$ tests result in very low $p$ values, showing a good significance of the models (Table S5 and S6 of the elec tronic supplementary material). In the next section (Tests and Validation of Correlations), the validity of the corre lations is tested against experimental results of model mixtures and real resources.

\section{Tests and Validation of Correlations}

\section{Results of HTL Experiments of the Test Points}

The use of different DOEs and several regression models led to the elaboration of 8 correlations for each mass yield. Yet, all correlations might not represent accurately exper imental results obtained with different model mixtures and real food processing residues. Therefore, we tested the validity of the correlations by comparing them with results obtained from the two model mixtures, as well as four real food processing residues. Table 6 recalls the composition of the chosen test points, and Fig. 7 shows the experi mental yields of the products for the six test points.

Figure 7 shows variations of the product yields depending on the starting biomass or model mixture. For instance, brewer's spent grains (BSG) produce the lower bio oil yield, as well as the higher proportion of organic matter recovered in the aqueous phase. A similar amount of char is obtained, when compared to other resources. The results obtained by HTL of BSG might be linked to the higher carbohydrate content of BSG compared to other resources which are richer in lignin (Table 6). In fact, we identified in previous sections that cellulosic fibers and sugars mainly produce char and water soluble organics 
Table 6 Composition of the model mixtures and food processing residues used for testing the correlations

\begin{tabular}{|c|c|c|c|c|c|c|}
\hline \multirow[t]{2}{*}{ Composition (wt\% daf) } & \multicolumn{6}{|c|}{ Model mixture/biomass } \\
\hline & Mixture 1 & Mixture 2 & $\begin{array}{l}\text { Blackcurrant } \\
\text { pomace }\end{array}$ & $\begin{array}{l}\text { Raspberry } \\
\text { achenes }\end{array}$ & BSG & Grape marc \\
\hline $\mathrm{x}_{1}$ : cellulose hemicellulose sugars ${ }^{\mathrm{a}}$ & 30.7 (glucose) & 30.6 (cellulose) & 30.6 & 38.7 & 68.5 & 30.3 \\
\hline $\mathrm{x}_{2}:$ proteins & 17.6 (glutamic acid) & 17.8 (glutamic acid) & 17.7 & 8.2 & 19.3 & 10.2 \\
\hline $\mathrm{x}_{3}$ : lignin & 36.3 (guaiacol) & 36.3 (alkali lignin) & 36.2 & 47.8 & 6.0 & 51.0 \\
\hline $\mathrm{x}_{4}$ : lipids & 15.4 (linoleic acid) & 15.4 (linoleic acid) & 15.5 & 5.3 & 6.2 & 8.5 \\
\hline
\end{tabular}

${ }^{\text {a }}$ Calculated by difference using the data from Table 1
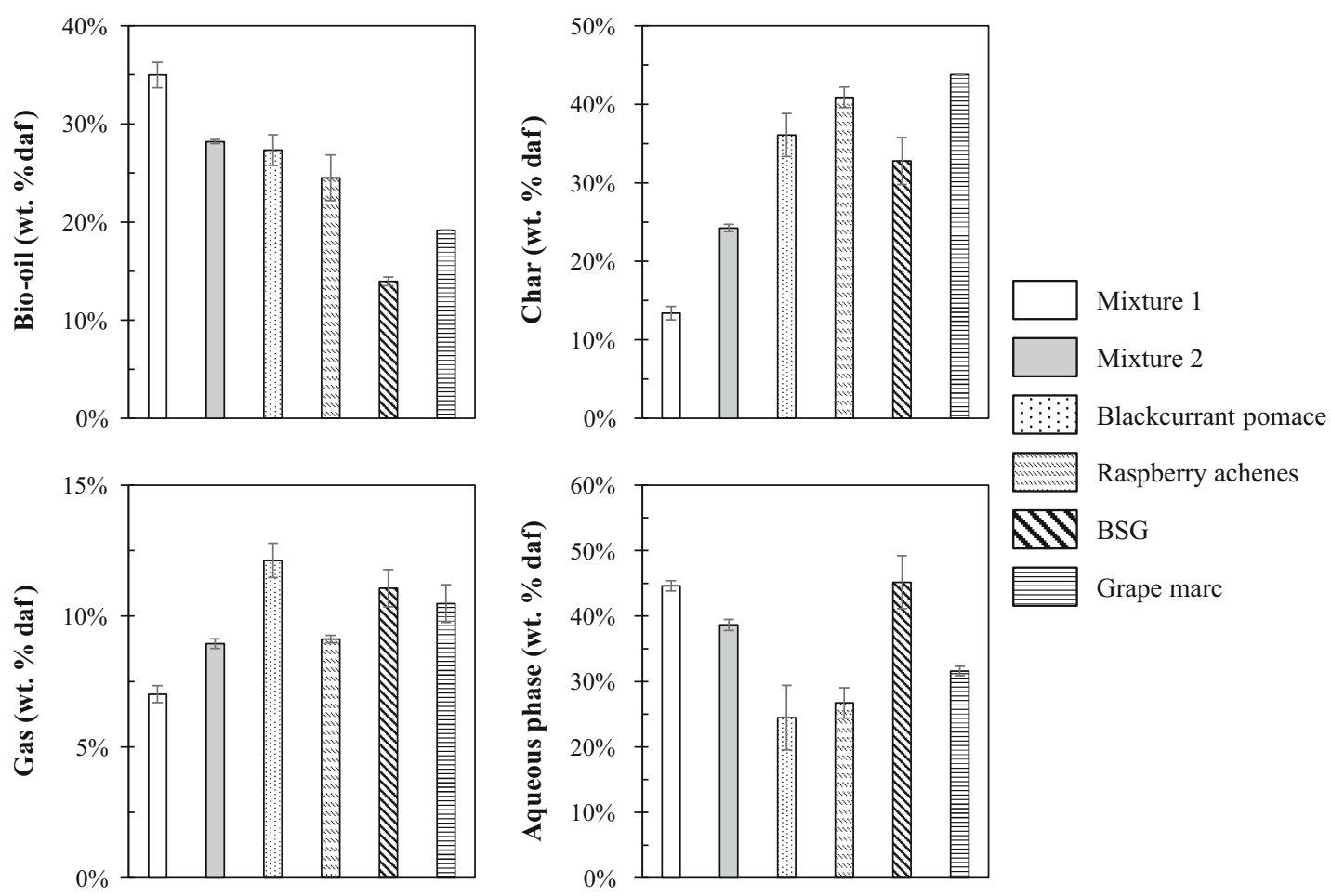
NIN BSG 产学 Grape marc

Fig. 7 Experimental yields produced by HTL of two model mixtures and four food processing residues (daf: dry ash free)

during HTL. As well, grape marc produces a relatively low bio oil yield and the highest char yield, which might result from the high fiber content in this biomass. Grape marc is especially rich in lignin, which leads to low bio oil and high char recovery, as observed in "Results of HTL Experiments" section from HTL of alkali lignin. In the next section, experimental results shown in Fig. 7 are compared with calculated yields obtained using the corre lations, with the objective of selecting appropriate equa tions to describe the mass yields as a function of the initial biochemical content of the biomass.

\section{Selection of the Correlations}

To select adequate correlations describing the mass yields from the initial biomass composition, experimental yields are compared with calculated yields in Fig. 8. To assess in a visual way the representativeness of correlations, we considered an interval of $\pm 5 \mathrm{wt} \%$ around each experi mental yield (dashed lines in Fig. 8).

The results presented in Fig. 8 show that few correla tions are able to predict the bio oil yields within $\pm 5 \mathrm{wt} \%$ of experimental yields. In the case of mixture 1, only 

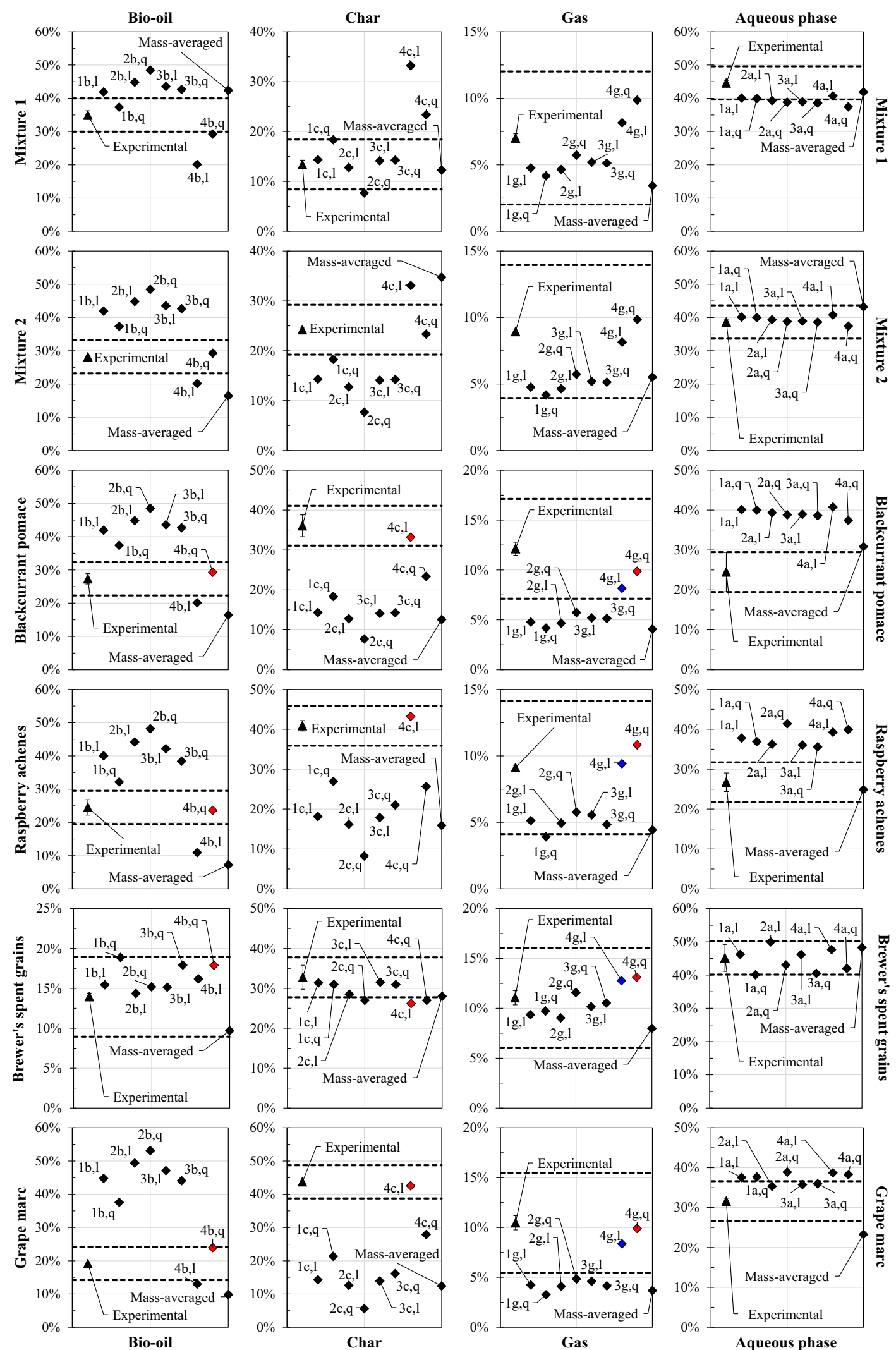

Fig. 8 Comparison between experimental and calculated yields using correlations 
correlation $1 b, q$ predicts with good accuracy the bio oil yield, with a slight overestimation of $2.4 \mathrm{wt} \%$. The second best correlation in this case is $4 b, q$, which underestimates the bio oil yield by $5.7 \mathrm{wt} \%$. This same correlation $(4 b, q)$ predicts well the bio oil yield in the case of mixture 2, with a slight overestimation of $1.1 \mathrm{wt} \%$. Experimental char yields for mixtures 1 and 2 are generally predicted with good accuracy by the correlations, even though correlations elaborated from model monomers $(1 b, l$ to $3 b, q)$ systemat ically underestimate the char yield in the case of mixture 2 . This results from the polymeric nature of fibers used in mixture 2, as discussed before in "Comparison of the Mass Yields" section. The same observation applies for the prediction of gas yields by most correlations. Finally, aqueous phase yields are overall well predicted by the correlations. Aqueous phase yields are systematically underestimated in the case of mixture 1 , which may be linked to an overestimation of the bio oil yield. From the results, it is possible to say that correlations obtained from model monomers cannot be applied to experimental results from HTL of model polymers, especially regarding the formation of bio oil and char. Several correlations can however be used to calculate the mass yields from the starting composition of the model mixture.

The comparison of the calculations with experimental yields for real resources show that some correlations are able to predict accurately the behavior of biomass during HTL. When considering the results for bio oil, it is observed that the correlation $4 b, q$ might be able to predict the mass yields within $\pm 5 \mathrm{wt} \%$ of experimental results for most resources. Other correlations might be more accurate for specific resources, but cannot be applied to the whole range of resources that we considered. For instance, cor relations obtained from HTL of model monomers $(1 b, l$ to $3 b, q$ ) seem to be more accurate for BSG, but they over estimate greatly the bio oil yields for the other three food processing residues. This is probably due to the different nature of fibers in BSG, which would be responsible for different reactivity. In fact, contrarily to the other three studied food processing residues, BSG are rich in carbo hydrate and poor in lignin (Table 6). Despite these differences, we chose correlation $4 b, q$ to model the bio oil yield, because it allows a good prediction of bio oil yields, between -0.9 and $+4.8 \mathrm{wt} \%$ of experimental yields.

The comparison of experimental results and calculations for char yields shows that correlation $4 c, l$ seems to be the most representative for most food processing residues. Using correlation $4 c, l$, char yields for blackcurrant pomace, raspberry achenes and grape marc are predicted with a maximum underestimation of $2.9 \mathrm{wt} \%$ and a maximum overestimation of $2.3 \mathrm{wt} \%$. However, the correlation $4 c, l$ seems less adapted to predict the char yield from HTL of BSG, which is underestimated by $6.6 \mathrm{wt} \%$. The different nature of fibers contained in BSG might explain this observation. Contrarily to the other three food processing residues, BSG are poor in lignin and especially rich in carbohydrate, which are more readily converted in sub critical water [24]. It is therefore likely that char formation pathways differ between BSG and the three other resour ces: while char is mainly due to bad hydrolysis for the three most lignin rich resources, it might result from recombi nation of reactive intermediates in the case of BSG. This could explain why the correlations based on the results from model monomers predict in a better way the char yield for BSG.

From the gas yields, the correlations $4 g, l$ and $4 g, q$ seem to be the most representative of HTL of real food pro cessing residues. In fact, the correlations obtained from HTL of model monomers only seem to be adapted in the case of BSG, but they underestimate the gas yields for the other three food processing residues. From a chemical point of view, this could mean that the gas formation pathways differ between BSG and the other resources: while gas is mainly produced from monomer degradations in the case of BSG, the main gas formation pathways for the three other resources could also result from the degradation of polymeric fibers. Nonetheless, we chose correlation $4 g, q$ which predicts the gas yields with a maximum underestimation of $-2.3 \mathrm{wt} \%$ and a maximum overestimation of $2.0 \mathrm{wt} \%$.

Finally, we see from the results that no correlation predicts accurately the aqueous phase yields for

Table 7 Coefficients of the predictive correlations chosen to calculate mass yields in HTL of food processing residues

\begin{tabular}{|c|c|c|c|c|c|c|c|c|c|c|c|c|}
\hline Product & Correlation $\mathrm{N}^{\circ}$ & $\mathrm{b}_{1}$ & $\mathrm{~b}_{2}$ & $\mathrm{~b}_{3}$ & $\mathrm{~b}_{4}$ & $b_{12}$ & $b_{13}$ & $b_{14}$ & $b_{23}$ & $b_{24}$ & $\mathrm{~b}_{34}$ & $\mathrm{R}^{2}$ \\
\hline Bio oil & $4 b, q$ & 0.05 & 0.00 & 0.00 & 0.95 & 0.18 & 0.79 & 0.45 & 0.23 & 0.44 & 0.30 & 0.998 \\
\hline Char & $4 \mathrm{c}, 1$ & 0.33 & 0.00 & 0.64 & 0.00 & & & & & & & 0.86 \\
\hline Gas & $4 g, q$ & 0.10 & 0.05 & 0.04 & 0.00 & 0.32 & 0.16 & 0.03 & 0.16 & 0.02 & 0.01 & 0.998 \\
\hline Aqueous phase ${ }^{\mathrm{a}}$ & $1(4 b, q+4 c, 1+4 g, q)$ & 0.48 & 0.05 & 0.68 & 0.95 & 0.50 & 0.94 & 0.42 & 0.39 & 0.42 & 0.28 & $0.91^{\mathrm{b}}$ \\
\hline
\end{tabular}


blackcurrant pomace and raspberry achenes. In the case of BSG, most correlations predict the mass yields within the $\pm 5 \mathrm{wt} \%$ interval, as well as some correlations in the case of grape marc $(2 a, l, 3 a, l$ and $3 a, q)$. Contrarily to other products, it is therefore not possible to select one existing correlation. We chose therefore to determine the correla tion for the aqueous phase by difference, as a linear com bination of correlations for bio oil, char and gas.

\section{Validation of the Correlations}

The previous section showed that some correlations are adequate to predict product yields from the initial bio chemical content of food processing residues. The chosen correlations are summarized in Table 7 . Correlation coef ficients are good $(0.860 .998)$, indicating a good fit of the models to the experimental data.

The low $p$ values obtained from the F tests (see Table S7 of the electronic supplementary material) show that the significance of the models is good ( $p$ val ues $<5.2 \times 10^{-5}$ ). In addition, observations made in the previous sections on contributions of biochemical com pounds to the various products are confirmed, when assessing the significance of the parameters (Table S7 of the electronic supplementary material)

- Bio oil yield: all parameters are significant at a level over $97 \%$, except $\mathrm{x}_{2}$ (proteins) and $\mathrm{x}_{3}$ (lignin).
- Char yield: all parameters are significant at a level over $99 \%$, except $\mathrm{x}_{2}$ (proteins) and $\mathrm{x}_{4}$ (lipids).

- Gas yield: all parameters are significant at a level over $98 \%$, except $\mathrm{x}_{4}$ (lipids) and $\mathrm{x}_{3} \mathrm{x}_{4}$ (binary interaction between lignin and lipids).

- Aqueous phase yield: all parameters are significant at a level over $99 \%$, as a result of the mathematical construction of this correlation. It is also consistent with the reaction network proposed by Valdez et al. [13], who suggest contributions of the biomolecules to both the aqueous phase and the bio oil prior to further degradation.

As can be seen from Table 7, quadratic models were chosen to represent the bio oil and gas yields, taking into account binary interactions between biomass components. Important binary interactions have for example been observed between carbohydrate and proteins, via Maillard reactions, confirming previous results from the literature [15]. On the contrary, a linear correlation was chosen to predict char yields from the carbohydrate and lignin con tents of the biomass. This indicates that the main char formation is due to the fiber content in the initial material, and that interaction pathways have less influence. Figure 9 shows the comparison between calculated yields and experimental results.

The correlations allow to predict with good accuracy experimental results for HTL of real food processing residues. Calculated yields vary from -0.9 to $4.8 \mathrm{wt} \%$ of
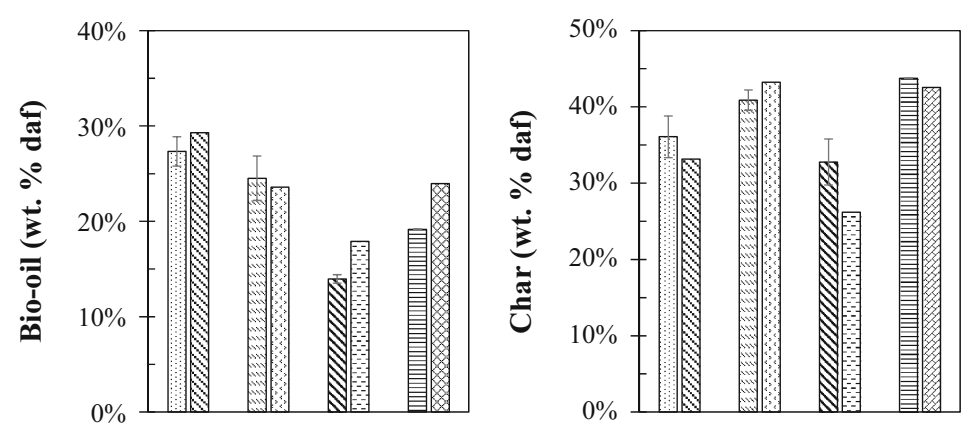

$\because \because$ Blackcurrant pomace (exp.)

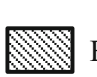

Blackcurrant pomace (calc.)

$\times$ Raspberry achenes (exp.)

Raspberry achenes (calc.)
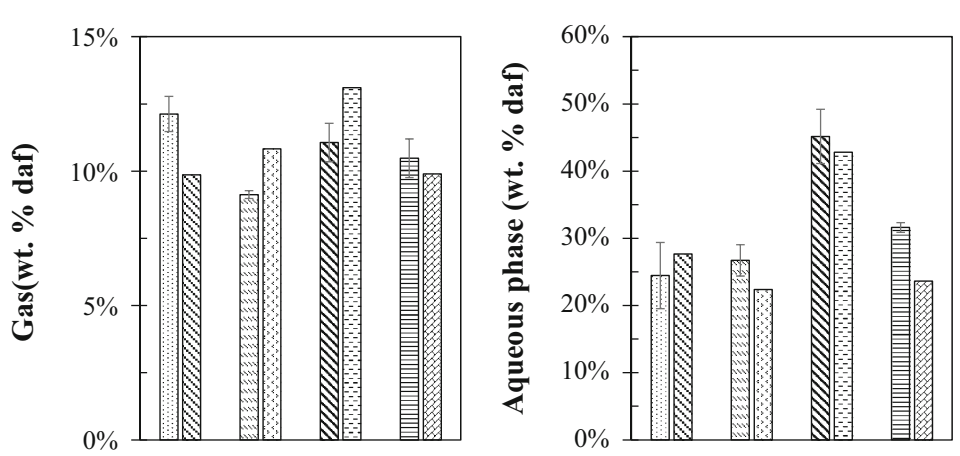

W Brewer's Spent Grain (exp.)

Brewer's Spent Grain (calc.)

Grape marc (exp.)

Grape marc (calc.)

Fig. 9 Comparison between calculated mass yields and experimental results from HTL of real food processing residues 

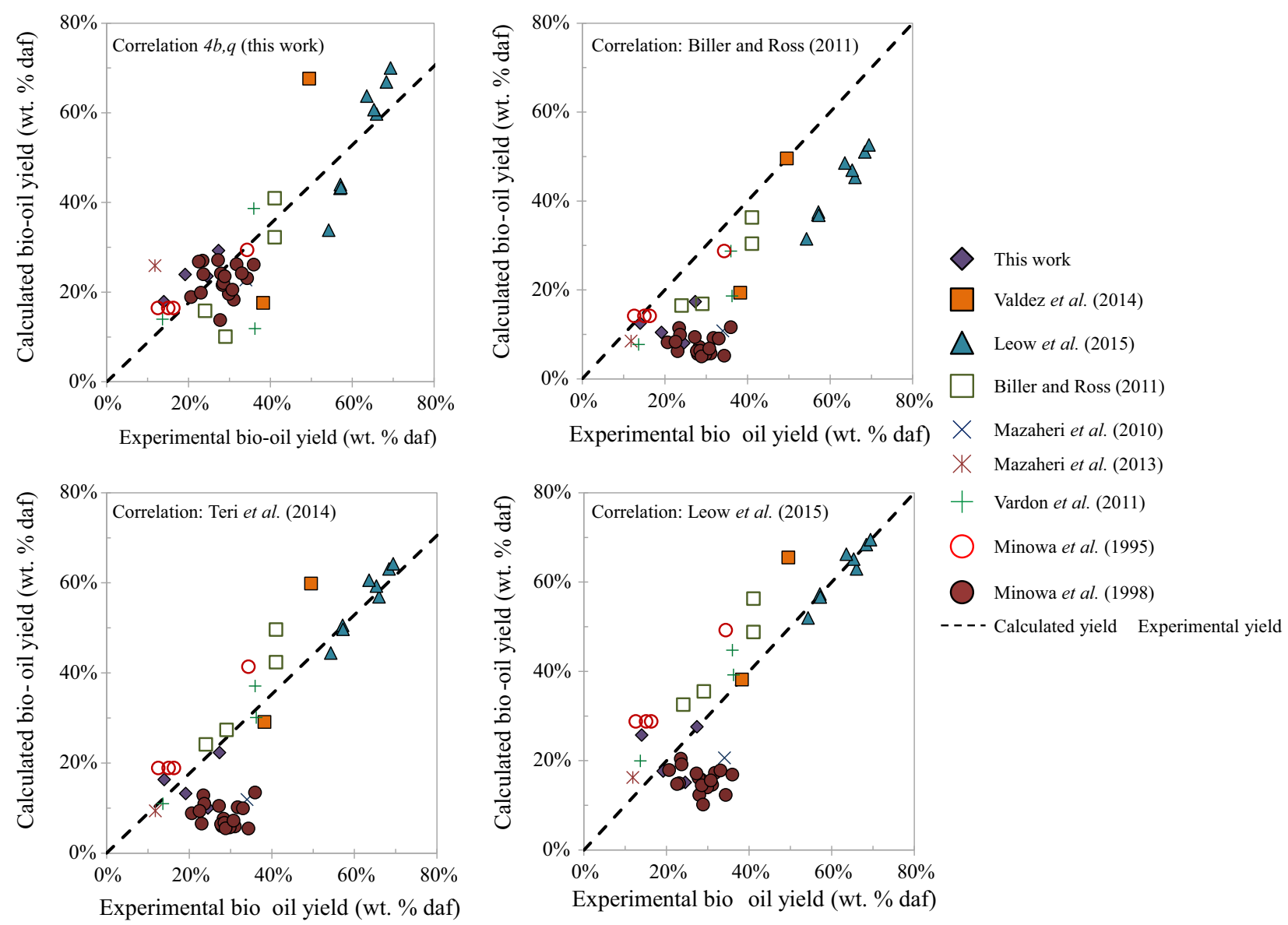

Fig. 10 Comparison of the correlations for calculating bio oil yields from the initial biomass composition (this work, [12 14, 16, 28 33])

experimental bio oil yields, -6.6 to $2.3 \mathrm{wt} \%$ of experi mental char yields, -2.3 to $2.0 \mathrm{wt} \%$ of gas yields and -8.0 to $3.2 \mathrm{wt} \%$ of aqueous phase yields. Considering experi mental errors, the chosen correlations are in good agree ment with HTL of real food processing residues.

In Fig. 10, we compare the prediction capability of our correlations with previously published correlations based on additivity laws $[12,14,16]$. To do so, we used studies from the literature reporting both the biochemical compo sition of their starting biomass and the bio oil yields, at close operating conditions to ours $\left(300^{\circ} \mathrm{C}\right)$. The objective was to diversify the scope of resources. Therefore, we included in the comparison algae [12, 13, 16, 28, 29], as well as lignocellulosic biomass and organic residues (this work, [28, 30 33]). The presented comparison was per formed exclusively for the bio oil yield, as other yields were not discussed by all previous studies. Yet, the cor relation for the char yield is able to accurately predict results from HTL of microalgae obtained by Valdez et al. [13] and Leow et al. [16]. Gas and aqueous phase yields are somewhat predicted with less accuracy (results not shown).
The results shown in Fig. 10 illustrate the good accuracy of our correlation to calculate the bio oil yields from HTL of several resources of different natures. The correlation developed in the present paper allows a good prediction of a large scope of bioresources, in comparison with corre lations developed specifically for microalgae. The largest discrepancies arise in the case of protein rich and lipid poor resources. In fact, in these cases, our correlation underestimates the bio oil yields reported in other studies (Biller and Ross [12], Vardon et al. [28], Valdez et al. [13], Leow et al. [16]). This is most likely due to the fact that we did not include a model polymer in our study to represent the protein content of the biomass, leading to discrepancies at high protein contents. Future work should be done to correct the correlations using a model protein instead of a model amino acid.

A better accuracy is obtained when comparing our cal culations to experimental results for lignocellulosic bio mass (Minowa et al. [30]) and organic residues such as manure, sewage sludge or municipal solid waste (Minowa et al. [31], Vardon et al. [28]), which have a lower protein 
Bio oil

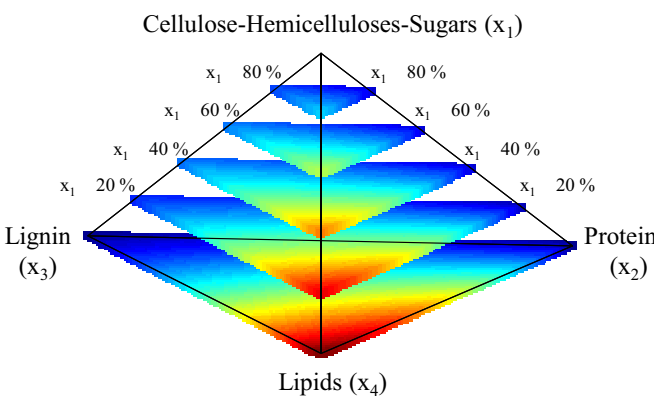

Gas

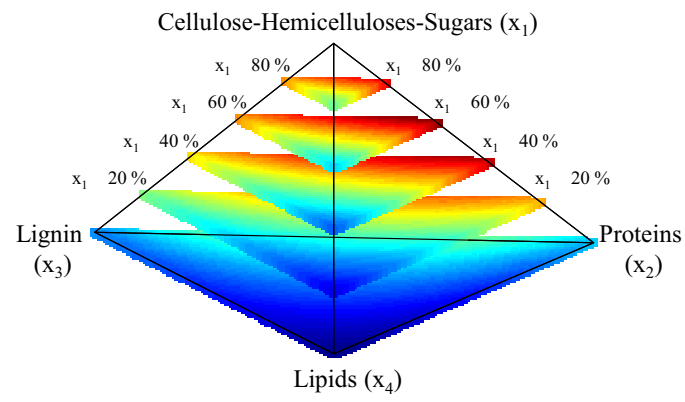

Char
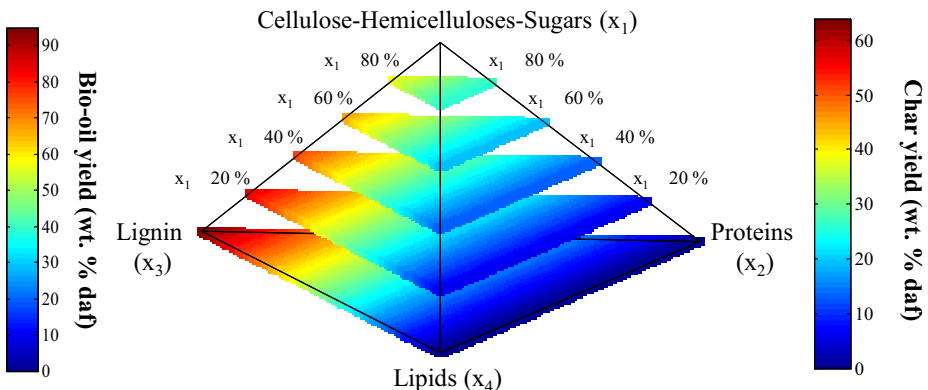

Aqueous phase

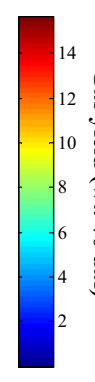

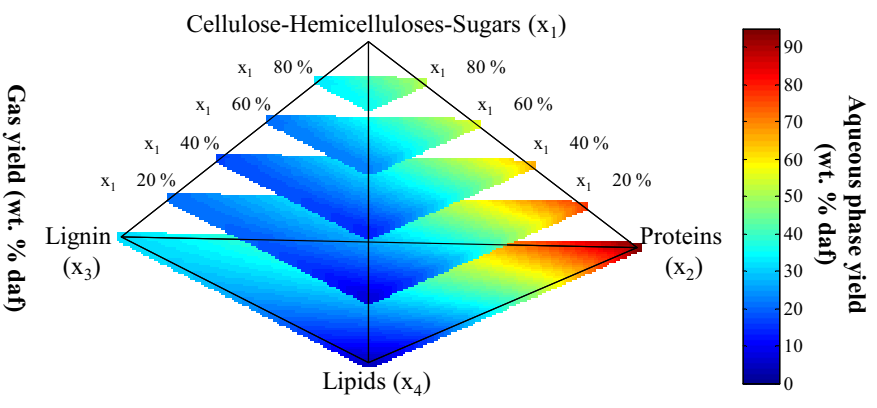

Fig. 11 Evolution of mass yields (wt \% of initial dry ash free matter) for HTL of food processing residues as a function of the initial biomass composition (fixed carbohydrate content: $0,20,40,60$ and $80 \mathrm{wt} \%$ daf)

content. In particular, a better accuracy towards lignocel lulosic resources is achieved by the fact that our model includes a variable for lignin. Note that discrepancies between calculations and experiments may also arise from the biomass characterization methods, which often differ between authors, as well as the product workup procedures. Bio oil yields can be influenced for instance by the nature of organic solvents used to perform the extraction [23, 34], and by the steps followed for bio oil recovery [35]. Despite the observed discrepancies, we conclude from Figs. 9, Fig. 10 that the correlations can be used to describe the evolution of mass yields from the initial biomass compo sition. This is what is illustrated in Fig. 11.

Figure 11 recalls the main observations made in this study, and show the main contributing species for each product:

- Lipids are the main contributors to the bio oil yield, but interaction phenomena have also been observed, such as between carbohydrate and proteins, or between proteins and lipids. Interactions between degradation products of carbohydrate and lignin correspond to condensation reactions that can benefit to bio oil formation, but also to char through polymerization.

- Fibers contribute the most to the char yield, either individually or through interaction reactions between monomers and reactive intermediates.
- As for the char yield, gas formation is driven by the fiber content of the biomass, as well as by Maillard reactions between carbohydrates and protein.

- Formation of water soluble organics is mostly the results of carbohydrate and protein degradation, and to a lesser extent of lignin depolymerization by hydrolysis.

\section{Conclusion}

This paper has presented a modelling study of hydrothermal liquefaction (HTL) of food processing residues using model compounds, selected from the characterization of blackcurrant pomace. By selecting appropriate model molecules, HTL of blackcurrant pomace could be reproduced with acceptable representa tiveness, especially when model polymers were used to represent the fiber content of the biomass. In this case, the bio oil was slightly overestimated by $1 \mathrm{wt} \%$, while char and gas yields were respectively underestimated by 8 and $3 \mathrm{wt} \%$. Using exclusively model monomers results in a lower representativeness towards HTL of blackcurrant pomace, evidencing the strong influence of the nature of model molecules (monomers or polymers) on HTL results. 
Studying hydrothermal conversion of model compounds alone, and in mixture of 2 to 4 compounds, allowed the identification of the main contributing species to product formation, as well as interaction phenomena. Lipids are the main contributors to the bio oil yield, while interaction reactions can also increase bio oil formation (e.g. carbo hydrate protein, carbohydrate lipid, protein lipid). As shown by the comparison between model mixtures and HTL of blackcurrant pomace, fibers contribute the most to the char yield, either individually or through interaction reactions between monomers and reactive intermediates (e.g. carbohydrate lignin monomers interaction). Gas for mation is also driven by the fiber content of the biomass, as well as some interactions (e.g. carbohydrate protein). Finally, formation of water soluble organics mostly results from carbohydrate and protein individual degradation, and to a lesser extent from lignin depolymerization by hydrolysis.

The hydrothermal conversion of model compounds, following several designs of experiments, led to the elab oration of correlations able to predict HTL results with good accuracy for the four studied real food processing residues. Quadratic correlations were chosen to predict the bio oil and gas yields, taking into account binary interac tions, while a linear correlation was chosen to calculate the char yield. This is the mathematical translation of the main contribution of fibers to char formation, with less influence of interaction pathways. Finally, the calculation of the aqueous phase yield was elaborated as a linear combination of other correlations. Overall, calculations are within -8.0 to $+4.8 \mathrm{wt} \%$ of experimental yields of the products, indi cating the good agreement between models and experi mental data. The obtained correlations were then validated on a larger scope of resources based on results from the literature, showing some limitations (e.g. protein rich lipid poor algae strains). Future work should focus on further validation of the correlations, for instance by including a model protein in the DOEs or by using native extracts of the biomass as model molecules to gain better representa tiveness. The expressions established in this work could nevertheless be useful tools to evaluate potential resources for the HTL process from straight forward information (biochemical composition), therefore avoiding the need for multiple scouting tests. The correlations could also be used to design biomass blends able to produce a standard quality oil in high yield, opening the way to co processing of different resources.

Acknowledgments The authors would like to acknowledge financial support from the French Research National Agency ANR (LIQHYD Project. Grant No. ANR 12 BIME 0003). The authors are also grateful to Marine Blanchin, Hélène Miller, Sébastien Thiery and Julien Roussely for technical support and help on analysis of the products.

\section{References}

1. van Swaaij, W., Kersten, S., Palz, W.: Biomass power for the world: transformations to effective use. Biomass power for the world: transformations to effective use, pp. 1734 (2015)

2. FAO: Food Wastage Footprint: Impacts on Natural Resources. FAO (2013)

3. Akiya, N., Savage, P.E.: Roles of water for chemical reactions in high temperature water. Chem. Rev. 102, 27252750 (2002)

4. Weingärtner, H., Franck, E.U.F.: Supercritical water as a solvent. Angew. Chem. Int. Ed. 44, 26722692 (2005)

5. Ruiz, H.A., Rodríguez Jasso, R.M., Fernandes, B.D., Vicente, A.A., Teixeira, J.A.: Hydrothermal processing, as an alternative for upgrading agriculture residues and marine biomass according to the biorefinery concept: a review. Renew. Sustain. Energy Rev. 21, 3551 (2013)

6. Toor, S.S., Rosendahl, L., Rudolf, A.: Hydrothermal liquefaction of biomass: a review of subcritical water technologies. Energy 36, 23282342 (2011)

7. Elliott, D.C., Biller, P., Ross, A.B., Schmidt, A.J., Jones, S.B.: Hydrothermal liquefaction of biomass: developments from batch to continuous process. Bioresour. Technol. 178, 147156 (2015)

8. Pedersen, T.H., Grigoras, I.F., Hoffmann, J., Toor, S.S., Daraban, I.M., Jensen, C.U., Iversen, S.B., Madsen, R.B., Glasius, M., Arturi, K.R., Nielsen, R.P., Søgaard, E.G., Rosendahl, L.A.: Continuous hydrothermal co liquefaction of aspen wood and glycerol with water phase recirculation. Appl. Energy 162, 10341041 (2016)

9. Barreiro, D.L., Prins, W., Ronsse, F., Brilman, W.: Hydrothermal liquefaction (HTL) of microalgae for biofuel production: state of the art review and future prospects. Biomass Bioenergy 53, 113127 (2013)

10. Déniel, M., Haarlemmer, G., Roubaud, A., Weiss Hortala, E., Fages, J.: Energy valorisation of food processing residues and model compounds by hydrothermal liquefaction. Renew. Sustain. Energy Rev. 54, 16321652 (2016)

11. Arturi, K.R., Kucheryavskiy, S., Søgaard, E.G.: Performance of hydrothermal liquefaction (HTL) of biomass by multivariate data analysis. Fuel Process. Technol. 150, 94103 (2016)

12. Biller, P., Ross, A.B.: Potential yields and properties of oil from the hydrothermal liquefaction of microalgae with different bio chemical content. Bioresour. Technol. 102, 215225 (2011)

13. Valdez, P.J., Tocco, V.J., Savage, P.E.: A general kinetic model for the hydrothermal liquefaction of microalgae. Bioresour. Technol. 163, 123127 (2014)

14. Teri, G., Luo, L., Savage, P.E.: Hydrothermal treatment of pro tein, polysaccharide, and lipids alone and in mixtures. Energy Fuels 28, 75017509 (2014)

15. Yang, W., Li, X., Li, Z., Tong, C., Feng, L.: Understanding low lipid algae hydrothermal liquefaction characteristics and path ways through hydrothermal liquefaction of algal major compo nents: crude polysaccharides, crude proteins and their binary mixtures. Bioresour. Technol. 196, 99108 (2015)

16. Leow, S., Witter, J.R., Vardon, D.R., Sharma, B.K., Guest, J.S., Strathmann, T.J.: Prediction of microalgae hydrothermal lique faction products from feedstock biochemical composition. Green Chem. 17, 35843599 (2015)

17. AFNOR, NF EN 147741 Biocombustibles solides Détermina tion de la teneur en humidité Méthode par séchage à l'étuve Partie 1: humidité totale Méthode de référence (2010)

18. AFNOR, NF V18 122 Aliments des animaux Détermination séquentielle des constituants pariétaux Méthode par traitement aux détergents neutre et acide et à l'acide sulfurique (2013)

19. AFNOR, NF EN 14775 Biocombustibles solides Méthode de détermination de la teneur en cendres (2010) 
20. Dote, Y., Inoue, S., Ogi, T., Yokoyama, S.: Distribution of nitrogen to oil products from liquefaction of amino acids. Bioresour. Technol. 64, 157160 (1998)

21. Dote, Y., Inoue, S., Ogi, T., Yokoyama, S.: Studies on the direct liquefaction of protein contained biomass: the distribution of nitrogen in the products. Biomass Bioenergy 11, 491498 (1996)

22. Tinsson, W.: Plans d'expérience: constructions et analyses statistiques. Mathématiques et Applications, vol. 67, 1st edn. Springer, Berlin (2010). doi:10.1007/978 3642114724

23. Anouti, S., Haarlemmer, G., Déniel, M., Roubaud, A.: Analysis of physico chemical properties of bio oil from hydrothermal liquefaction of blackcurrant pomace. Energy Fuels 30, 398406 (2015)

24. Karagöz, S., Bhaskar, T., Muto, A., Sakata, Y.: Comparative studies of oil compositions produced from sawdust, rice husk, lignin and cellulose by hydrothermal treatment. Fuel 84, 875884 (2005)

25. Akgül, G., Kruse, A.: Influence of salts on the subcritical water gas shift reaction. J. Supercrit. Fluids 66, 207214 (2012)

26. Changi, S., Zhu, M., Savage, P.E.: Hydrothermal reaction kinetics and pathways of phenylalanine alone and in binary mixtures. ChemSusChem 5, 17431757 (2012)

27. Yin, S., Tan, Z.: Hydrothermal liquefaction of cellulose to bio oil under acidic, neutral and alkaline conditions. Appl. Energy 92, 234239 (2012)

28. Vardon, D.R., Sharma, B.K., Scott, J., Yu, G., Wang, Z., Schideman, L., Zhang, Y., Strathmann, T.J.: Chemical properties of biocrude oil from the hydrothermal liquefaction of Spirulina algae, swine manure, and digested anaerobic sludge. Bioresour. Technol. 102, 82958303 (2011)

29. Minowa, T., Yokoyama, S., Kishimoto, M., Okakura, T.: Oil production from algal cells of Dunaliella tertiolecta by direct thermochemical liquefaction. Fuel 74, 17351738 (1995)

30. Minowa, T., Kondo, T., Sudirjo, S.T.: Thermochemical lique faction of indonesian biomass residues. Biomass Bioenergy 14 517524 (1998)

31. Minowa, T., Murakami, M., Dote, Y., Ogi, T., Yokoyama, S.: Oil production from garbage by thermochemical liquefaction. Bio mass Bioenergy 8, 117120 (1995)

32. Mazaheri, H., Lee, K.T., Bhatia, S., Mohamed, A.R.: Subcritical water liquefaction of oil palm fruit press fiber for the production of bio oil: effect of catalysts. Bioresour. Technol. 101, 745751 (2010)

33. Mazaheri, H., Lee, K.T., Mohamed, A.R.: Influence of tempera ture on liquid products yield of oil palm shell via subcritical water liquefaction in the presence of alkali catalyst. Fuel Process. Technol. 110, 197205 (2013)

34. Valdez, P.J., Dickinson, J.G., Savage, P.E.: Characterization of product fractions from hydrothermal liquefaction of nan nochloropsis sp. and the influence of solvents. Energy Fuels 25 , 32353243 (2011)

35. Barreiro, D.L., Riede, S., Hornung, U., Kruse, A., Prins, W.: Hydrothermal liquefaction of microalgae: effect on the product yields of the addition of an organic solvent to separate the aqueous phase and the biocrude oil. Algal Res. 12, 206212 (2015) 